\title{
The phonology, phonetics, and diachrony of Sturtevant's Law
}

\author{
Anthony D. Yates \\ University of California, Los Angeles \\ adyates@ucla.edu
}

\begin{abstract}
This paper presents a systematic reassessment of STURTEVANT'S LAW (Sturtevant 1932), which governs the differing outcomes of Proto-Indo-European voiced and voiceless obstruents in Hittite (Anatolian). I argue that Sturtevant's LAw was a conditioned pre-Hittite sound change whereby (i) contrastively voiceless word-medial obstruents regularly underwent gemination (cf. Melchert 1994), but gemination was blocked for stops in pre-stop position; and (ii) the inherited [ \pm voice] contrast was then lost, replaced by the [ \pm long] opposition observed in Hittite (cf. Blevins 2004). I provide empirical and typological support for this novel restriction, which is shown not only to account straightforwardly for data that is problematic under previous analyses, but also to be phonetically motivated, a natural consequence of the poorly cued durational contrast between voiceless and voiced stops in pre-stop environments. I develop an optimality-theoretic analysis of this gemination pattern in pre-Hittite, and discuss how this grammar gave rise to synchronic Hittite via "transphonologization" (Hyman 1976, 2013). Finally, it is argued that this analysis supports deriving the Hittite stop system from the Proto-Indo-European system as traditionally reconstructed with an opposition between voiceless, voiced, and breathy voiced stops (contra Kloekhorst 2016, Jäntti 2017).
\end{abstract}

\section{Keywords}

Hittite - Indo-European - diachronic phonology - language change - phonological typology 
This paper is concerned principally with the historical development of the Hittite oral stop (i.e., plosive) consonants-specifically, with the synchronic phonological contrast between those orthographically represented with geminate stops and those represented with singleton stops, and how this contrast developed diachronically from Proto-Indo-European (PIE). The origin of this distribution was first treated systematically by Sturtevant (1932), who made the seminal observation in (1): ${ }^{1}$

(1) "[O]riginal voiceless stops are usually represented in Hitt. by doubled consonants wherever the cuneiform makes this possible, while the tendency is to write single $p, t(d)$ and $k(g)$ for original voiced stops and voiced aspirates" (Sturtevant 1932, 2).

While this observation is popularly referred to as StURTEVANT'S LAW(STVL), its status remains controversial and its nature incompletely understood. ${ }^{2}$ At least the questions in $(2 \mathrm{a}-\mathrm{c})$ are disputed, whereas (2d) has not previously received rigorous attention:

(2) a. Is the etymological distribution stated in (1) consistently maintained and thus (1) truly a "law" (in approximately the Neogrammarian sense)? Or is it instead just a "tendency" as described by Sturtevant (thus also explicitly Pozza 2012, 277)?

b. What is the nature of the geminate/singleton stop contrast within Hittite? Does the stated relationship between Hittite geminate/singleton stops and the reflexes of voiceless/voiced stops in the non-Anatolian Indo-European languages represent a different phonological contrast than in PIE and thus reflect a sound change, or is it just a spelling rule?

1 Sturtevant $(1932,2)$ credits the inspiration for this observation to his Yale graduate student C.L. Mudge, who first pointed out to him that PIE * $p$ appears in Hittite as - $p p-$; this finding is implicit already in Mudge's $(1931,252)$ etymologies of Hitt. lappiyaš 'fever; heat' and alpa'cloud', which he correctly relates to NIE forms with unambiguous reflexes of voiceless and voiced stops respectively (e.g., Gk. $\lambda \dot{\alpha} \mu \pi \omega$ 'shine', Lith. lópe 'light' < * $p$; Lat. albus 'white', Gk.

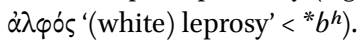

2 Pedersen $(1938,227)$ was first to refer to $(1)$ as a "law" (Gesetz); for a detailed history of scholarship on the issue, see Pozza (2011, 29-33; 2012, 257-258 n. 1). 
c. If a sound change, is it Hittite that has innovated as assumed by Sturtevant? Or was it the ancestor of the non-Anatolian IE languages that innovated as argued by Kloekhorst (2016)?

d. If a sound change, in what phonological environments did it apply?

These questions are addressed in this paper, the primary aim of which is to advance a new analysis of STVL. I argue that STVL must be understood as a sound law proper, and more precisely, that it states a pre-Hittite (i.e., postProto-Anatolian) conditioned sound change whereby: ${ }^{3}$

(3) a. Contrastively voiceless obstruents (i.e., voiceless stops $+{ }^{*} h_{2}$; but excluding ${ }^{*} s$ and ${ }^{*} h_{1}$ ) developed into geminate obstruents (thus ${ }^{*} t>[\mathrm{t} \mathrm{t}]$, etc.).

b. Contrastively voiced obstruents (i.e., voiced stops + preserved ${ }^{*} h_{3} /$ "lenited" * $h_{2}$ ) developed into non-voiced non-geminate obstruents in most phonological contexts (thus ${ }^{*} d>[\mathrm{t}]$, etc.).

c. All stops became non-geminate stops when preceding another stop.

I assume that pre-Hittite had four phonemic dorsal fricatives contrasting for voicing and labialization (most likely, ${ }^{*} / \chi \mid,{ }^{*} / \chi^{\mathrm{w}} /,{ }^{*} / \mathrm{b} /$, and ${ }^{*} / \mathrm{B}^{\mathrm{w}} /$ ) as the reflexes of PIE ${ }^{*} h_{2}$ and ${ }^{*} h_{3}$ in different conditioning environments, the voiced set occurring where ${ }^{*} h_{3}$ was preserved or where ${ }^{*} h_{2}$ was subject to lenition in ProtoAnatolian (PA; cf. 2.1 below). ${ }^{4}$ Like voiceless stops, voiceless dorsal fricatives were subject to gemination as part of STVL, whereas the other pre-Hittite voiceless fricatives $* / \mathrm{s} /$ and $* / \mathrm{h} /\left(<\mathrm{PIE} * h_{1}\right)$ - which lack phonemically voiced counterparts-were not. The precise generalization, then, is that only contrastively voiceless obstruents (or equivalently, non-sibilant consonantal obstruents) were affected by gemination. Note, however, that for conciseness all subsequent references to "(voiceless) obstruents" should be taken to exclude ${ }^{*} s$ and ${ }^{*} h$, unless otherwise indicated.

3 This study is confined to the Hittite evidence for STVL; it thus excludes the STVL-like phenomena that are found in Palaic and Cuneiform Luwian, which require separate treatments elsewhere (see further discussion in 5.4 below).

4 See Kloekhorst (2006, 97-100, 106) on the emergence of labialized "laryngeals" in PA, and Melchert (2011) on preserved ${ }^{*} h_{3}$ in PA and Hittite (cf. Kloekhorst 2008, 838, 946; contra Melchert 1994, 72-74). The phonetic values assumed here for Hittite accord well with Kümmel's $(2007,227-236)$ identification of PIE ${ }^{*} h_{1},{ }^{*} h_{2}$, and ${ }^{*} h_{3}$ as ${ }^{*} / \mathrm{h} /,{ }^{*} / \chi /$, and ${ }^{*} / \mathrm{s} /$ respectively (cf. Weiss 2016). These values will be used here in transcription of (pre-)Hittite forms, but for PIE forms I retain the traditional symbols. 
The remainder of this paper is structured as follows. Section 2 lays out some assumptions underlying this proposal that relate to the questions posed in (2a-b). I contend that STVL is a "law" rather than a "tendency" (cf. Kloekhorst 2016; contra Pozza 2011, 2012); that Hittite orthographic geminate stops contrast phonologically with singleton stops by length rather than by voice (cf. Melchert 1994, 14-21, Kloekhorst 2014, 544-547; contra Kimball 1999, 46, 94-95, i.a.); and that since these $[ \pm$ long] stops correspond etymologically with [ \pm voice] stops standardly reconstructed for PIE, a real phonological change must have taken place between PIE and Hittite. ${ }^{5}$

Section 3 develops the hypothesis that STVL was a pre-Hittite sound change by which surface voiceless obstruents were subject to gemination and phonologically contrastive obstruent voicing was eliminated. I then introduce some data that problematizes this hypothesis, cases in which a PIE voiced stop that was phonetically devoiced by an immediately following voiceless stop unexpectedly yields a non-geminate stop in Hittite. Previous solutions to this problem are discussed, including Kloekhorst's (2016) recent arguments that PIE did not have voicing assimilation and the radical revision of the PIE stop system that he advocates partially on this basis.

An alternative analysis of these problematic forms is developed in section 4. I provide empirical evidence that pre-Hittite word-medial voiceless stopsincluding, significantly, phonemically voiceless stops-regularly develop into Hittite non-geminate stops when immediately preceding another stop. This development is argued to be phonetically motivated, the natural result of the poorly cued durational contrast between voiceless and voiced stops in this environment. Finally, I propose a formal analysis of STVL that correctly accounts for these developments.

Section 5 concludes. I evaluate the implications of this analysis of STVLfirst, for the reconstruction of the PIE phonological system, and then for diachronic phonological typology. In the former respect, I argue in particular that the Hittite evidence does not support the revisions to the traditional reconstruction of this system proposed by Kloekhorst (2016), and in the latter, that STVL does represent a case in which a historical obstruent voicing contrast was reanalyzed as a length contrast (as argued already by Melchert 1994, 18-21; contra Kloekhorst 2016, Jäntti 2017). Lastly, I discuss some issues related to STVL that remain outstanding and directions for future research.

5 Hittite geminates are here represented as [+long] and non-geminates as [-long], but I do not intend any theoretical claim as to whether geminates are better analyzed as underlyingly long or underlyingly heavy (on which issue see, e.g., Ringen and Vago 2010, Davis 2011). 


\section{On the nature of Sturtevant's Law}

The central claim of STVL-that Hittite scribes generally used geminate and singleton spellings to represent "original" (i.e., PIE as traditionally reconstructed) voiceless and (breathy) voiced stops respectively-has been generally accepted for more than half a century (Čop 1963, 23-41; cf. Melchert 1994, 16, Kimball 1999, 90-91). Some (relatively) uncontroversial examples of STVL are provided in $(4-5)$ below, where the reflexes of PIE voiced and breathy voiced stops — which had merged already in PA—as well as * $h_{3}$ in (4) clearly contrast with those of voiceless stops and ${ }^{*} h_{2}$ in $(5):^{6}$

(4) a. PIE * $k^{w} o^{\prime}-b^{h} i>$ Hitt. kuwāpi 'where?' $\mathrm{ADV}$

b. PIE *péd-om > Hitt. pēdan 'place' N.NOM/ACC.SG

(cf. Ved. -bhis (INSTR.PL); Gk. - $\varphi$ I)

c. PIE * $d^{h} e^{h^{h}-\bar{o} m}>$ Hitt. tēkan 'earth' N.NOM.SG

d. PIE *lóh ${ }_{3} w-e i>$ Hitt. lahui 'pours' 3SG.NPST.ACT (cf. Gk. $\pi \varepsilon \dot{\delta} 0 \nu$ ) (cf. Gk. $\lambda \circ \varepsilon ́ \omega)$

(5) a. PIE * $h_{1}$ ópi >> Hitt. äppa 'back' ADV

b. PIE *-te- >> (e.g.) Hitt. dattēni 'you take' 2 PL.NPST.ACT

(cf. Gk. - $\tau \varepsilon$, OCS -te; Lat. -tis)

c. PIE *twék-mo >> Hitt. tuekkan 'body' ANIM.ACC.SG

(cf. Ved.tvácam)

d. PIE *péh $h_{2}-w r>$ Hitt. pahhur 'fire' N.NOM/ACC.SG

As noted in section 1, however, other aspects of STVL remain controversial. Two of the more significant points of contention are treated in 2.1 and 2.2 below.

6 In (4-5) the voicing quality of the stop is in all cases uncontroversial, even if other aspects of the etymology are disputed. For the etymologies in $(4 b-c)$ and $(5 b-d)$ see Kloekhorst (2008, s.vv); for (4a) see HEG I: 693-694 with references; for (4d) see Melchert (2011); and for (5a) see Melchert (2009, 335-336; 2012, 176). In (4d) and (5d), the relevant segment is intervocalic after the fusion of the ${ }^{*} h_{2} / h_{3}+{ }^{*} w$ sequence into a unitary labialized fricative in PA (cf. n. 4 above). 


\section{1 “Law" or "tendency"?}

In Sturtevant's (1932) own formulation of what eventually came to be known as STVL (given in (1) above), he described the correspondence relationship between Hittite orthographic geminate/singleton stops and PIE voiceless/ voiced stops as a "tendency." This description was motivated by a number of examples in which the spelling of a Hittite stop appeared to mismatch this generalization, such as Hitt. mekki- 'much; many' vs. Gk. $\mu$ '́ $\gamma \alpha \varsigma^{\prime}$ 'big; great'. However, Sturtevant (1932, 9-12) himself suggested that some of these exceptions were principled, and attempted to provide linguistic explanations for the discrepancies. $^{7}$

This approach was adopted in subsequent scholarship, which provided now generally accepted explanations for apparent counter-examples. Some of these were demonstrated to be based on incorrect etymologies, such as Sturtevant's equation of Hitt. eku/aku- 'drink' (< PIE * $h_{1} e g^{w h_{-} ;}$cf. TA/B yok- 'id.', Lat. èbrius 'drunk') with Lat. aqua 'water' (< PIE * $h_{2} e k^{w_{-}-e h_{2}}$ or * $\left(h_{1}\right) a k^{w}-e h_{2}$; cf. Goth. ahva, OE $\bar{e} a$ 'river'). ${ }^{8}$ Still others were shown to be the result of conditioned prehistoric sound changes-most significantly, PA LENITION, which caused voicing of PA voiceless stops (and ${ }^{*} h_{2}$ ) after stressed long vowels and between unstressed vowels. ${ }^{9}$ Some examples of PA lenition and its Hittite reflexes are given in (6):10

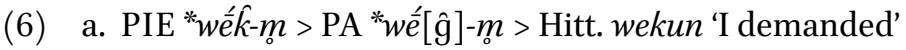

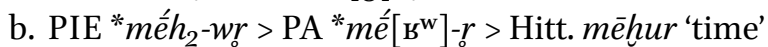

7 Sturtevant (1932) suggested that the geminate $-k k$-in Hitt. mekki- was due to the analog-

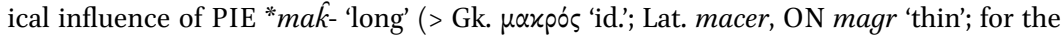
root's $a$-vocalism, see Nussbaum 1976, 103). However, the need for such an explanation was obviated by the advent of the laryngeal theory; both Greek and Hittite forms can be traced back straightforwardly to the PIE root ${ }^{*} m e g h_{2}-$ (see Melchert 1994, 76-77).

On the etymology of Hitt. eku/aku- 'drink' see n. 25 below. The exact etymology of Lat. aqua remains disputed (cf. De Vaan 2008, 48-49 with references), but its Germanic cognates make the reconstruction of a voiceless labiovelar ${ }^{*} k^{w}$ secure.

9 On PA lenition generally see Eichner (1973) (cf. Melchert 1994, 6o-62, 68-69; 2019); for a reformulation in moraic terms, see Adiego (2001) (cf. Yoshida 2011).

10 For the derivation of (6a), see Melchert (2014) (cf. LIV²: 672-673; contra Kloekhorst 2008, 996-997); the root is that of Ved. vaś- 'want' and Gk. < $\dot{\varepsilon} x \omega^{\prime} v$ 'willing'. On (6b) see Eichner (1973). For (6c), the pre-form is uncertain; Melchert (1994, 61) argues for a historical compound *sóm-wetes-t- 'of the same year' (cf. Hrozný 1917, 93 n. 2), whereas Kimball (1999, 223) suggests instead *só-wetes-t- 'of this year', yet by either derivation the * $t$ of the second member lies between two unstressed vowels and is thus subject to lenition. For a different account of (6b) and (6c) — but still involving lenition — see Kloekhorst $(2008,567-568$, 739-740). 
c. PIE *só(m)-wetes-t-? > PA *só(m)-we[d]es-t- > Hitt. šāwitišt- / šāudišt'(calf) born this year'

Despite these findings, the view that STVL is only a "tendency" has recently been reasserted by Pozza (2011, 712-713; 2012, 277). While she correctly points out that some exceptions to the law await a satisfactory linguistic explanation, ${ }^{11}$ I nevertheless maintain the view that remaining genuine counter-examples are few (similarly, Kloekhorst 2016, 214 n. 1; cf. Kimball 1999, 90-91), and that if the analysis laid out in section 4 below is correct, this set would shrink even further. Accordingly, I will assume in section 3 that STVL was in fact a "law" and thus states a regular correspondence relationship between Hittite orthographic geminate/singleton obstruents and pre-Hittite voiceless/voiced obstruents, which have the same voicing as cognate obstruents in the NIE languages except when subject to inner-Anatolian conditioned developments. Before proceeding further, however, it is necessary to clarify the nature of this "law" - in particular, what phonological contrast is encoded in geminate vs. singleton spellings of Hittite obstruents, and in turn, whether they are indicative of a real phonological change in the prehistory of Hittite; these issues are treated in 2.2 below.

\subsection{Phonological change or orthographic practice?}

It has been the communis opinio since Sturtevant (1932) that Hittite shows a contrast between orthographic geminate and singleton obstruents which is regularly maintained intervocalically. This contrast can be observed across lexical items, some words being spelled consistently with an intervocalic geminate obstruent (e.g., appanzi 'they take' $<$ PIE ${ }^{*} h_{1} e p$-), others consistently with a nongeminate obstruent (e.g., adanzi/atanzi 'they eat' $<$ PIE $h_{1}$ ed-). The phonemic contrast is confirmed, moreover, by minimal pairs like (7):

\begin{tabular}{|c|c|c|c|}
\hline & GEMINATE & vs. & SINGLETON \\
\hline a. $\langle h a-a t-t a-a n-z a\rangle$ & 'pierce.PTCP.ANIM.NOM.SG' & $\langle h a-t a-a n-z a\rangle$ & 'dry.PTCP.ANIM.NOM.SG' \\
\hline b. $\langle p a d-d a-a n\rangle$ & 'dig.PTCP.N.NOM/ACC.SG’ & $\langle p a-t a-a-a n\rangle$ & 'foot.ANIM.GEN.PL' \\
\hline c. $\langle$ še-ek-kán $\rangle$ & 'know.PTCP.N.NOM/ACC.sG' & $\langle$ še-kán $\rangle$ & 'cubit.N.NOM/ACC.SG' \\
\hline
\end{tabular}

11 Such as gemination of etymological (breathy) voiced stops after ${ }^{*} r$ - e.g., har (ap) $p$ - '(re)associate; join' < PIE ${ }^{*} h_{3} e{ }^{h}{ }^{h}$ - — which cannot plausibly be attributed to devoicing per se; for further discussion and examples of this phenomenon, see Melchert $(1994,20,153)$ and Pozza (2012, 270-272) with references. 
Yet despite general agreement about the existence of the orthographic contrast observed in (7), its synchronic phonological interpretation has been much debated (cf. Hoffner and Melchert 2008, 35). The two competing proposals in (8) are predominant in the literature on this issue: ${ }^{12}$

(8) a. Hittite stops are distinguished phonologically by voice: $-t t / d d^{-}=[\mathrm{t}]$, $-t / d-=[\mathrm{d}]$, etc.

b. Hittite stops are distinguished phonologically by length: $-t t / d d-=[\mathrm{t}]$, $-t / d-=[\mathrm{t}]$, etc.

A fundamental difference between the hypotheses in (8) is whether STVL constitutes a real sound change. Under (8a), inherited voiceless obstruents are continued in Hittite as voiceless obstruents, and voiced obstruents as voiced obstruents (thus Kimball 1999, 45-47, i.a.). This is essentially the null hypothesis: no actual phonological change has taken place between PA and Hittite. STVL would thus be a purely orthographic rule, a statement of the Hittite practice of using geminate consonant signs to represent voiceless obstruents and singleton signs for voiced obstruents.

Under (8b), in contrast, STVL states a real phonological change: inherited voiceless obstruents developed into [+long] obstruents and voiced stops into [-long] obstruents. Hittite obstruents thus synchronically contrast for length rather than for voice: labial [p:] vs. [p]; coronal [t:] vs. [t]; dorsal [k:, $\mathrm{k}^{\mathrm{w}}, \chi_{\mathrm{i}}$, $\left.\chi^{: \mathrm{w}}\right]$ vs. $\left[\mathrm{k}, \mathrm{k}^{\mathrm{w}}, \chi, \chi^{\mathrm{w}}\right]$. Melchert $(1994,14-21)$ and more recently Kloekhorst (2014, $544-547 ; 2016,215^{-217}$ ) have both argued in support of such a synchronic length contrast; I treat briefly below the three arguments in (9), which in my view constitute the strongest evidence for this analysis:

(9) a. Orthographic parallelism with geminate sonorants.

b. Intervocalic geminate obstruents close a preceding syllable.

c. Lack of synchronic voicing assimilation.

The first argument that supports a length distinction in Hittite obstruents is (9a) comparison with the sonorants, which similarly exhibit an orthographic contrast between geminate and singleton spellings (e.g., âri 'arrives' vs. ārri

12 Traditionally, the Hittite contrast between geminate and singleton obstruents has been described as "fortis" vs. "lenis" (Pedersen 1933, 22-23), which are essentially neutral labels that sidestep the issue of their phonetic realization and phonological representation. See Kimball (1999, 94-95), Pozza (2011, 33-38), and Kloekhorst (2016, 214 n. 2) for full overviews of previous scholarship and the various proposals put forward. 
'washes'). Such spelling contrasts do not plausibly reflect a difference in voicing: not only are phonemic voicing contrasts in sonorants typologically uncommon ( $<5 \%$ of the world's languages per Blevins 2018,29$)$, but more importantly, analyzing geminate sonorants as voiceless makes little sense from a historical perspective - in particular, examples in which they arise intervocalically via assimilation to another voiced consonant, such as Hitt. wellu- 'meadow' ( $<$ PIE *wél-nu-) or mimmanzi 'they refuse' (< PIE *mí-mn-ñti). ${ }^{13}$ However, these same examples are easily explained under the view that orthographically geminate sonorants are real geminates, which often develop by assimilation of consonant clusters (Blevins 2004, 171). It is very likely, then, that Hittite scribes used geminate and singleton spellings to encode a length contrast in sonorant consonants; moreover, a natural further assumption is that the same orthographic practice was used to encode the same phonological contrast in obstruents.

In addition, there is prosodic evidence suggesting that Hittite orthographic geminate stops are real phonological geminates. Specifically, it appears that (9b) intervocalic geminates close a preceding syllable. Within the synchronic grammar, this property is evident from the prosodic behavior of non-mid vowels, which in some cases surface as short under word stress before a geminate stop, including those that derive historically from single voiceless stopse.g., initial [á] in Hitt. hatta 'pierces', [í] in kitta lies' (where $\left.-t t-<{ }^{*} t\right) .{ }^{14}$ This behavior is significant, since Hittite does not permit lexical words with short stressed vowels in open syllables, which thus undergo lengthening in this position (Melchert 1994, 107, 131; cf. Yates 2017, 79-80), e.g., (10a-b). Short stressed non-mid vowels in syllables closed by a consonant are permitted, however, e.g., $($ (oc- $-\mathrm{d}):^{15}$

13 On Hitt. wellu- see Kloekhorst (2008, 998) with references. For the pre-form of Hitt. mimma- (and its cognate Gk. $\mu^{\prime}(\mu \nu \omega$ 'stand fast; remain') see Jasanoff $(2003,128-131)$ (cf. Sturtevant 1933, 133).

14 The former derives from PIE * $h_{2}$ ét-or, the latter from PIE * kéy-or with analogical introduction of the productive 3SG.MID ending *--to(r) (cf. LIV 2: 274, 320; Kloekhorst 2008, $330-331,473-475)$. Kloekhorst (2014, 419-420; 2016, 215) attributes the short [í] in kitta to pre-Hittite shortening of *íl (< *éi) in closed non-final syllables, which is plausible; it should be noted, however, that I reject Kloekhorst's $(2014,256-307$; 2016, 215-216) further claim that Old Hittite [a:] in closed syllables shortened to [a] in Middle Hittite, as it rests on the false premise that the relative incidence of plene spelling is linguistically significant (for arguments against this view, see Kimball 2015 and Yates 2016).

15 For a detailed treatment of these examples see Yates $(2017,79-84)$. As discussed there, Hittite also has non-mid vowels in closed syllables that do lengthen under stress and thus contrast phonemically with those in (1oc-d). For instance, the Hittite participle suffix -ant-has such a lengthening vowel, seen (e.g.) in PTCPL.ANIM.NOM.SG [a.tá:nts] '(having) eaten', spelled plene $\langle a$-da-a-an[-za] $\rangle$ (cf. (1oc), only spelled non-plene $\langle a-t / d a-a n-z i\rangle)$. 
(10) a. Hitt. /-í/ (LOC.SG): išš $[$ [i.s:-í: ] 'in the mouth'

b. Hitt. /kís-/ 'become': kīsari [kí.sa.ri] 'becomes' (3SG.NPST.MID)

c. Hitt. /-ántŝi/ (3PL.NPST.ACT): adanzi [a.tán.țsi] 'they eat'

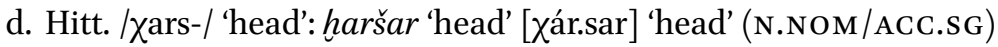

In failing to undergo lengthening under stress, the pre-geminate root vowels of hatta and kitta pattern with the non-mid vowels in closed syllables in (1ocd) and against those in open syllables in (1oa-b). These facts can be unified under the assumption that Hittite orthographic geminates are phonological geminates and thus close a preceding syllable just like a consonant cluster.

The last point (9c) concerns regressive obstruent voicing assimilation (Melchert 1994, 17-18; cf. Kloekhorst 2016, 214-215), which is observed in the majority of the ancient IE languages and standardly reconstructed for PIE (cf. Mayrhofer 1986, 110). This process is stated in rule-based form in (11):16

(11) Regressive Voicing Assimilation:

[-sonorant $] \rightarrow[\alpha$ voice $] /$ _ [-sonorant, $\alpha$ voice $]$

"Obstruents (incl. */s/) assimilate to the voicing quality of a following obstruent."

Hittite presents a mixed picture with respect to (11). On the one hand, there is compelling evidence that this process was operative prehistorically; for instance, the verbal root eku/aku- 'drink'-discussed in 2.1 above-has an invariant singleton stop in its basic inflectional paradigm $\left(<{ }^{*} g^{w h}\right)$, but its imperfective stem is akkuške- with a geminate root-final stop due to prehistoric devoicing by the initial * $s$ of the suffix ${ }^{*}$-ske- and then the regular application of STVL-i.e., Hitt. akkuške- < PIE * $\left[\mathrm{h}_{1} \mathrm{k}^{\mathrm{w}-s k e ́-}\right]{ }^{*} / \mathrm{h}_{1} \mathrm{eg}^{\text {wh }}$-ské-/ (Čop 1955, 68, Melchert 1994, 17; see additional examples in (16c-e) and further discussion in 5.1 below).

On the other hand, there are forms in which (11) does not apply and which thus suggest that (9c) voicing assimilation is no longer synchronically operative (cf. Melchert 1994, 17-18). The non-application of (11) in Hittite can be seen most clearly in verbal forms at stem boundaries before voiceless obstruentinitial endings, such as 2SG.NPST.ACT $-(\check{s}) \check{s} i(/$-si/) and 3SG.PST.ACT $-(t) t a$

16 At the PIE stage, (11) was part of a broader assimilatory process (formalized in (47) below) that neutralized laryngeal feature contrasts $([ \pm$ voice $],[ \pm$ spread glottis $])$ in obstruent clusters (discussed further in 5.1 and $n$. 61 below); this process was simplified after the loss of the historical distinction between breathy voiced and plain voiced stops in PA (Melchert 1994, 6o). 
(/-t:a/). ${ }^{17}$ If it were the case that (i) Hittite had regressive voicing assimilation and (ii) voice was contrastive in Hittite obstruents (per (8a) above), one would expect to find that stem-final voiced obstruents are devoiced by these endings; thus (e.g.) the Hittite root $e k u / a k u$ - 'drink' — discussed in 2.1 above - should have 2SG.NPST.ACT forms spelled $x\langle e-e k-k u-u s ̌ s-s ̌ i\rangle$ and 3 SG.PST.ACT forms spelled $x\langle e-e k-k u-u t-t a\rangle$ with orthographic geminate representing the devoiced stop $\left(\left[\mathrm{k}^{\mathrm{w}}\right]\right)$. Since the observed forms are rather $\langle e-k u-u \check{s}$-š $i\rangle$ and $\langle e-k u-u t-t a\rangle$ with singleton stop, ${ }^{18}$ these premises cannot be correct. Yet if instead Hittite obstruents were distinguished by length (per (8b) above), the absence of synchronic voicing assimilation is predictable: $\langle e-k u-u s ̌-s ̌ i\rangle$ and $\langle e-k u-u t-t a\rangle$ would spell the same non-geminate $\left[\mathrm{k}^{\mathrm{w}}\right]$ that is attested throughout the verb's inflectional paradigm..$^{19}$ With respect to assimilation, then, $(8 \mathrm{~b})$ makes better predictions than (8a) and is to be preferred on these grounds.

In sum, the Hittite orthographic and phonological facts in (9) are better explained if Hittite obstruents show a phonemic length contrast rather than the voicing contrast traditionally assumed for PIE. This difference entails that a real sound change has taken place — not just a change in phonetic implementation but one with non-trivial consequences for the phonological system, since it affects at least (i) whether or not any intervocalic obstruents close a preceding syllable; and (ii) whether or not voicing assimilation is operative. In the next section I therefore pursue the hypothesis that STVL was a sound change governing the development of Hittite geminate and non-geminate obstruents.

\section{Sturtevant's Law as a regular sound change}

The preceding section laid the foundation for the hypothesis that STVL was a real sound law whereby pre-Hittite voiceless and voiced obstruents devel-

17 Given that the 2SG.PST.ACT shows geminate spellings only in post-consonantal position, I assume underlying /-si/ with synchronic gemination in this environment (for prehistoric gemination of * $s$ in consonant clusters, see Melchert 1994, 150-153). The phonological interpretation of the 3 SG.PST.ACT ending is more problematic; I assume here that Hittite has an allomorph /-tra/ with development of a real "prop vowel" vis-à-vis PIE */-t/ (cf. Eichner 1975, 80, Melchert 1994, 175-176, i.a.), but see Yoshida (1991, 1993, 2001) for a different view.

18 These spellings are attested beside $\langle e-u k$-ši $\rangle$ and $\langle e-u k-t a\rangle$; the $\langle u k\rangle /\langle k u\rangle$ alternation spells a labialized stop $\left[\mathrm{k}^{\mathrm{w}}\right]$ (Lindemann 1965; cf. Melchert 1994, 92).

19 Note, however, that invariant $\left[\mathrm{k}^{\mathrm{w}}\right]$ is not the historically expected outcome; under the analysis developed in sections $3-4$ below, $\left[\mathrm{k}^{\mathrm{w}}\right]$ is phonologically regular in all inflectional forms except the 2SG.NPST.ACT, where attested $\langle e-k u-u s ̌$-š $i\rangle$ with $\left[\mathrm{k}^{\mathrm{w}}\right]$ has analogically replaced expected ${ }^{\mathrm{x}}\langle e-e k-k u-u \check{s}$-ši $\rangle$ with $\left[\mathrm{k}^{\mathrm{w}_{\mathrm{i}}}\right]$ on the basis of the rest of the paradigm. 
oped regularly into Hittite geminate and non-geminate obstruents respectively. These developments are represented schematically in (12):

\section{Changes via SturTevant's LAW}

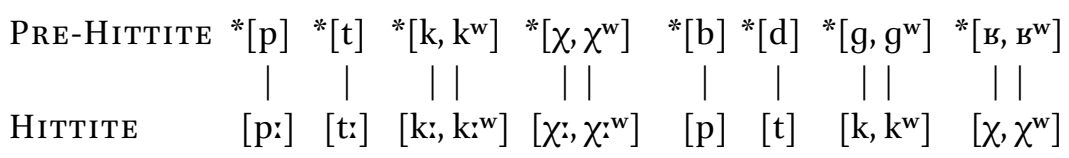

This section treats the evidence for this proposal in more detail. I restrict this treatment to Hittite stops in word-medial position, where it is generally agreed that the contrast between geminates and non-geminates is robust and the orthography typically allows this contrast to be realized. Word-initial and word-final stops are not treated here because, except perhaps under special conditions, the cuneiform writing system permits only singleton consonants at word edges, and what little evidence is available suggests that already in pre-Hittite voicing was non-contrastive in these environments (see further $\mathbf{5 . 2}$ below). Focusing, then, on word-medial obstruents, I discuss the positive evidence for the developments in (12) in 3.1. I then present in 3.2 several Hittite forms containing stops that unexpectedly fail to develop as in (12); two proposed solutions to this problem are outlined and assessed, with special attention paid to Kloekhorst's (2016) recent analysis and its implications for the prehistory of the Hittite stop system.

\subsection{Evidence for Sturtevant's Law}

As discussed in section 2, there is ample evidence that PIE voiceless and voiced obstruents surface respectively as geminate and non-geminate obstruents in Hittite, thus exhibiting the STVL developments laid out in (12). Some evidence for these developments in intervocalic position was cited already in (4-5) above; further support is provided by the Hittite forms below, where the non-geminate reflexes of inherited voiced obstruents in (13) contrast with the geminate reflexes of voiceless obstruents in (14): ${ }^{20}$

20 For the etymologies of $(13 a-c)$ and $(14 b-c)$ see Kloekhorst (2008, s.vv), and further on (14b) Goedegebuure (2010), whose comparison with CLuw. zanta confirms derivation from PIE *kmt-. For the correct pre-form of (14a) — viz., without root-final laryngeal—see Melchert $(2012,175)$ (cf. LIV: 684; contra Kloekhorst 20o8, 369). 
(13) a. PIE * $d^{h} e^{h} b^{h} u>$ Hitt. tēpu 'little; few' N.NOM/ACC.SG

(cf. Ved. dabhrá-)

b. PIE *wód-r > Hitt. wātar 'water' N.NOM/ACC.SG

c. PIE *yugóm $\rangle$ Hitt. yukan 'yoke' N.NOM/ACC.SG

(14) a. PIE * $h_{2}$ wóp-ei >> Hitt. huwappi 'throws' 3SG.NPST.ACT

b. PIE *kmíntō/a $>(>)$ Hitt. katta 'down; beside'

(cf. Ved. vápati) ADV

c. PIE *sók-r > Hitt. šakkar 'excrement' (cf. Gk. $\varkappa \alpha \tau \dot{\alpha} / \varkappa \alpha \dot{\alpha} \omega)$ N.NOM/ACC.SG

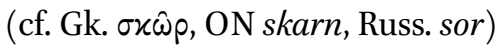

For non-intervocalic word-medial positions, the evidence for STVL is considerably more limited. The dearth of evidence must be attributed at least in part to orthographic practice: a pre- or post-consonantal geminate could be represented by an orthographic singleton, and in fact, it appears that this practice was preferred in cases where a more "faithful" spelling of the geminate would result in a less "faithful" representation of the word's phonological shape on the whole (e.g., by introducing an "empty" vowel). ${ }^{21}$ Nevertheless, there is evidence that voiceless obstruents underwent gemination before sonorant consonants, before *s, and after another obstruent-e.g., (15), (16), and (17) respectively (phonetic transcription used for explicitness where surface forms may differ from underlying forms): ${ }^{22}$

(15) PIE *pi-proh $y$-ñti $>>$ Hitt. $\langle p a-r i-i p-p a-r i-y a-a n-z i\rangle$ 'blow' 3PL.NPST.ACT

21 Hittite forms that are attested with a pre- or post-consonantal geminate thus tend to be attested with singleton spellings of the geminate stop as well-for instance, the stem of (15) is spelled $\langle$ pa-ri-pa-ri- $\rangle$; (17a) is spelled $\langle$ har-ta-ga-aš $\rangle$; and (17b) is spelled $\langle l i-i k$-ta $\rangle /\langle l i-$ $n i-i k-t a\rangle$. Note also the spelling alternations in (19-20) below.

22 For the etymologies of (15), (16a-d), and (17), see Kloekhorst (2008, s.vv) (cf. LIV 2 : 286-287 on (16d); NIL: 343-345 on (17a)). On the phonology of (15) see in detail Yates and Zukoff $\left(2018,212\right.$ n. 21). (16e) is the imperfective to lak-, on which see Jasanoff $\left(2003,15^{-1} 5^{2}\right.$, passim). The derivation of (17b) refers specifically to the allomorph of the 3 SG.PST.ACT ending with "prop vowel" (discussed in n. 17 above); since this allomorph occurs exclusively after obstruents (incl. *s; cf. Melchert 1994, 179-180), it should reflect the phonologically regular development in this environment. (17c) was probably in origin an instrument noun *'drinking vessel' to the root of Hitt. eku/aku- 'drink'; this yielded pre-Hittite *akuttar, from 
(16) a. PIE * dék ${ }^{w} s-y e-t i>$ Hitt. $\langle t e-e k-k u-u s ̌-s ̌ i-e z-z i\rangle$ 'shows' 3SG.NPST.ACT

b. PIE * péh $\left.{ }_{2} s-h_{2} e r\right\rangle(>)$ Hitt. $\left.\langle p a-a h-h a-a \check{s}-h a\rangle\right\rangle$ 'I protect' 1SG.NPST.ACT

c. PIE * $h_{2} u[\mathrm{k}-\mathrm{s}] \hat{k e ́}-s i>\mathrm{Hitt}$. $\left\langle h u-u k-k i-i{ }^{2}-k i-s ̌ i\right\rangle$ 'you conjure' 2SG.NPST.ACT.IPFV

d. PIE * $h_{2} u[\mathrm{k}-\mathrm{s}] \hat{k e ́} / o ́-n t i>\mathrm{Hitt}$. 〈hu-uk-ki-iš-kán-zi〉 'slaughter' 3PL.NPST.ACT.IPFV

e. Pre-Hitt. *la[k-s]ké > Hitt. $\langle l a-a k-k i-s ̌-k[i]\rangle$ 'incline!' 2SG.IMP.ACT.IPFV

(17) a. PIE * $h_{2 o} r t k o->$ Hitt. 〈har-tág-ga-aš 〉 bear'

ANIM.NOM.SG

LÚ〈har-ta-ak-ki〉 'bear-man'

ANIM.DAT.SG

b. PIE *- $t>$ (e.g.) Hitt. $\langle l i-i n-k a t-t a\rangle$ 'swore' 3SG.PST.ACT

c. PIE * $h_{1}\left[\mathrm{k}^{\mathrm{w}-\mathrm{t}]}\right] r o->>$ Hitt. $\langle a-k u-u t$-tar-aš $\rangle$ '(ritual functionary)' ANIM.NOM.SG

In order to ensure that the data in $\left(15^{-17}\right)$ illustrate the regular outcome of STVL, these examples include only Hittite forms in which (i) the relevant cluster is etymologically secure; (ii) the cluster existed as such in pre-Hittite (i.e., just prior to STVL); and (iii) the geminate obstruent lacks any plausible inter- or intraparadigmatic analogical source. For pre-sonorant obstruents especially, these restrictions impose fairly serious limitations on the usable evidence. ${ }^{23}$ However, it is likely significant that -in contrast to the situation for etymological voiceless stops in pre-stop contexts (see 4.1 and 5.3 below) - there are numerous examples of synchronic geminate obstruent-sonorant clusters, which can be found, e.g., in (18) the 1PL of verbal paradigms; in (19) verbal stems derived with the suffix -nu-; and in (20) isolated lexical items of unclear etymology:

which the attested Hittite form then arose by hypostasis ('one of the drinking-vessel'; see Yakubovich 2006a on this pattern).

23 Many examples of obstruent-sonorant sequences in the ancient IE languages come from suffixation of the thematic adjectival suffixes ${ }^{*}-r o-,{ }^{*}-l o-,{ }^{*}-n o-$ to a root. However, these forms do not directly bear upon the regular development of pre-Hittite obstruent-sonorant clusters via STVL due to the earlier sound change PA *-C\{r,l\}o\{s,m\}\# > pre-Hitt. *-Ca\{r,l\}\# (Melchert 1993; 1994, 87-88), which likely involves developments similar to the Latin "ager-rule" (see Weiss 2011, 123). 
(18) a. $\langle[a] p-p u-u ́-e-n i\rangle$ 'we take' 1PL.NPST.ACT

b. $\langle s e-e k-k u-e-n i\rangle,\langle s e-e k-k u-u ́-e-n i\rangle$ 'we know' 1PL.NPST.ACT

c. $\langle$ tar-ah-hu-u-e-ni 'we overcome' 1PL.NPST.ACT

(19) a. 〈ha-aš-ši-ig-ga-nu-wa-an-zi $\rangle,\langle h a-a \check{s}$-ši-ik-nu-an-zi $\rangle$ 3 PL.NPST.ACT 'satiate'

b. $\langle t i-i t-t a-n u-a n-z i\rangle,\langle t i-i t-n u-a n-z i\rangle$ 'install' 3 PL.NPST.ACT

(20) a. $\langle w a-a t-t a-r u\rangle,\langle w a-a t-r u\rangle$ 'well; source' N.NOM/ACC.sG

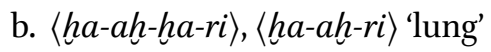
N.NOM/ACC.SG

The absence of a synchronic restriction against geminate obstruent-sonorant clusters is most easily explained if no such restriction existed diachronically either; the Hittite forms in (18-20) thus indirectly support the historical development directly observed in (15) above.

Finally, there is some evidence to suggest that voiceless fricatives underwent lengthening before stops as part of STVL. Their development is difficult to assess because PIE ${ }^{*} h_{2}$ and ${ }^{*} h_{3}$ were regularly lost historically before stops (with compensatory lengthening of the preceding vowel; see Melchert 1994, 67-69), but Hittite forms with - $h$-t- clusters at morpheme boundaries like idālawahti 'you treat ill' (2SG.NPST.ACT) and katterrahteni 'you make inferior' (2PL.NPST.ACT) show that these fricatives were analogically restored in certain alternating paradigms, probably already in pre-Hittite, and thus should have been present when STVL took place.

There is one lexical item that may shed light on the regular historical outcome of these restored fricatives: Hitt. lah(h)u- 'pour'. As shown by Melchert (2011), this verb derives from the PIE root * $l e h_{3} w$ - (cf. Lat. lavō, Gk. $\lambda \circ \varepsilon$ ' $\omega$ 'wash') and is thus predominantly attested with the non-geminate fricative - $h u$ - that is phonologically expected from a pre-Hittite voiced fricative $* / \mathrm{b}^{\mathrm{w}} /\left(<{ }^{*} h_{3} w\right)$ e.g., 3SG/PL.NPST.ACT lahuillahuanzi (OS; see CHD L-N: 13-15). However, a few forms with a geminate fricative - hhu- are also found. Melchert $(2011,130)$ observes that among the original "athematic" forms of this verb the geminate fricative occurs only in paradigm cells in which it preceded a voiceless 
obstruent-initial inflectional ending: before */s/ in 3SG.PST.ACT lahhusš; and before */t/ in 2SG.NPST.ACT $\langle l a-a h-h u-u t-t i\rangle$ and 2PL.IMP.ACT $\langle l a-a h$-hu-tén $\rangle$. He thus attributes these geminate fricatives to regular sound change, the result of prehistoric devoicing of root-final ${ }^{*} / \mathrm{B}^{\mathrm{w}} /$ by the following obstruent and the subsequent application of STVL as in (21):

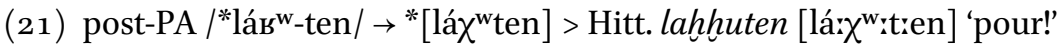
2PL.IMP.ACT

The assumption that contrastively voiceless fricatives underwent gemination in pre-stop position as part of STVL therefore accounts neatly for the distribution of $-h h u$ - in the inherited paradigmatic forms of $l a h(h) u$ - 'pour'. This development also expands the basis for the later analogical spread of this geminate, which is attested three times in innovative "thematic" forms of the verb $\left(2 \times 3\right.$ SG.NPST.ACT lahhuwai; 2 PL.IM P.ACT lähhuwaten).$^{24}$

The collective weight of the examples discussed above has led the majority of scholars to accept that Hittite word-medial obstruents were governed by STVL_-at minimum, as a regular relationship between singleton/geminate spellings of these obstruents and their voicing specification $([ \pm$ voice $])$ in PIE as traditionally reconstructed (cf. 2.1 above). Most of the controversy thus surrounds a relatively small set of apparent counter-examples and how these should be explained.

This set includes, on the one hand, a prominent group of ablauting radical hi-verbs that show an alternation between root-final singleton and geminate obstruents in their strong and weak stem forms, e.g., aki 'dies' vs. akkanzi 'they die', ištapi 'stops up' vs. ištappanzi 'they stop up'. Whether these should be explained by phonology or analogy is disputed: Kloekhorst $(2008,65,98$; 2014, 553-559) argues that this pattern is the result of PA lenition triggered by the preceding ${ }^{*} o$, whereas Melchert (2012) contends it spread interparadigmatically from ${ }^{*} h_{2}$-final roots where lenition was phonologically regular. Which

24 An analogical account of -hhu- in lahhutti and lahhuten is unlikely. Had gemination of the root-final fricative been blocked before stops, -hhu- would have been regular only in 1SG and 3SG.PST.ACT verb forms, which seem like a limited basis for its intraparadigmatic spread. It also encounters chronological problems. The analogical spread of the geminate is most likely a NH phenomenon since it is not attested prior to NS texts, yet these "athematic" verb forms can hardly have been remade by NH speakers, who would have substituted productive "thematic" forms (like lähhuwaten). However, positing an early spread is also problematic, since it is then difficult to explain why the forms of the verb attested in OS or MS texts never show an analogical geminate. 
of these accounts is correct is not a matter of primary concern here (but see n. 30 below), since in either case these apparent exceptions to STVL can be explained.

On the other hand, this set includes a smaller group of forms containing PIE voiceless stops which surface in Hittite spelled consistently singleton and which cannot be attributed to lenition or to analogy. These forms are treated in 3.2 below.

\subsection{Counter-evidence to Sturtevant's Law?}

Melchert (1994, 61) and Kloekhorst (2016, 214-215) have identified several Hittite forms that are problematic for STVL as understood in (12). These Hittite words and their PIE pre-forms are given in (22) below. ${ }^{25}$ In each case, the relevant segment is a PIE labiovelar stop immediately preceding */t/, a context in which it would have surfaced as voiceless ${ }^{*}\left[\mathrm{k}^{\mathrm{w}}\right]$ in PIE regardless of its underlying [voice] specification because of the regressive voicing assimilation process in (11) above; ${ }^{26}$ these voiceless labiovelar stops are expected to develop into Hittite geminates via STVL (i.e., Hitt. $\left.{ }_{-}-k k u-\left[k^{w_{i}}\right]\right)$, but are attested in Hittite only with singleton spelling, which suggests that this development did not occur:

(22) a. PIE *né[ $\left[\mathrm{k}^{\mathrm{w}}-\mathrm{t}\right]-\mathrm{s}>$ Hitt. nekuz (mehur) '(time) of evening' GEN.SG

b. PIE * $h_{1} e ́\left[\mathrm{k}^{\mathrm{w}-\mathrm{t}}\right]>$ Hitt. ekutta 'drank' 3SG.PST.ACT

c. PIE * $h_{1} e ́\left[\mathrm{k}^{\mathrm{w}}-\mathrm{t}\right] u>$ Hitt. ekuddu 'let him/her drink!'

d. PIE * $s(o)\left[\mathrm{k}^{\mathrm{w}} \mathrm{t}\right] h_{2}$-ố $i$ Hitt. šakuttai / šakutāe 'thighs' N.NOM/ACC.PL

25 On (22a) see NIL: $5^{\circ} 5^{-513}$ with references and the discussion in 3.2 .2 below. I follow Kloekhorst (2008, 236-237) (contra $\left.L I V^{2}, 231\right)$ in reconstructing a root formation for $(22 \mathrm{~b}$ ) and (22c); this does not preclude a parallel "Narten formation" reflected in Tocharian and perhaps Latin (per Kim 2000), but such a formation would not directly yield the attested Hittite forms. For (22d), I propose a PIE pre-form with * $o$-stem inflection (building on Normier apud Kühne 1986, 103 n. 61; cf. Melchert 1994, 61, Kloekhorst 2008, 703-704). This form is directly continued in Hittite and indirectly in Ved. sákthi- 'thigh', which shows analogical generalization of the weak stem preconsonantal allomorph; for the pattern, compare Hitt. haštai- 'bone' vs. Ved. ásthi 'id..

26 With respect to (22b), it should be noted that even if PIE did have a process of wordfinal obstruent voicing (see n. 68 below), it is likely that only post-vocalic obstruents were affected (as pointed out by Yoshida 2002, 168); devoicing of the preceding labiovelar is thus expected as in the other examples in (22). 
Of the examples in (22), the most important is (22a). It could be the case that the singleton stop in (22b) and (22c) has been restored by intraparadigmatic analogy, since the root-final stop did not undergo devoicing in the majority of paradigm cells (e.g., PIE * $\mathrm{h}_{1}$ ég $^{\text {wh }}$-mi $]>$ Hitt. ekumi). Similarly, it is conceivable that the absence of geminate spellings for (22d) is an accidental gap (cf. Kloekhorst 2008, 704), since the word is attested just four times (see CHD Š: 8o$81)$. However, the same cannot be the case for (22a), where there is no plausible basis for analogy, ${ }^{27}$ and which occurs more than thirty times with the singleton stop spellings in (23a) but never geminate spellings like (23b) (see CHD L-N: 434-435):

(23) a. $\langle n e-k u-u z\rangle,\langle n e-k u-z a\rangle,\langle n e-k u-u z-z a\rangle$

b. ${ }^{\mathrm{x}}\langle n e-e k-k u-u z\rangle, \mathrm{x}\langle n e-e k-k u-z a\rangle,{ }^{\mathrm{x}}\langle n e-e k-k u-u z-z a\rangle$

Given the unambiguous evidence in (23), it is attractive to seek a unified explanation for the consistently non-geminate spellings in all of the forms in (22). Two such explanations have been proposed, and will be discussed in turn in 3.2.1 and 3.2.2 below.

\subsubsection{Unexpected Hittite $-k u$ - for - $k k u$ - per Melchert 1994}

To account for apparent counter-examples to STVL like (22), Melchert (1994, 61) posits that in all word-medial positions $\mathrm{PIE}{ }^{*} k^{w}$ underwent voicing to PA ${ }^{*}{ }^{w}$. Yet while the resulting voiced stop would then correctly yield the attested Hittite non-geminate stop $-k u$ - $\left(\left[\mathrm{k}^{\mathrm{w}}\right]\right)$ in all of these forms, Melchert's hypothesis encounters several issues. The first is a lack of phonetic motivation-in particular, in the environment relevant to (22) (cf. Melchert 1994, 17-18). Even if it were the case that the voicing assimilation rule in (11) had ceased to be operative, the emergence of voicing before a voiceless stop is phonetically unnatural, as it is precisely in this position that stop voicing is hard to produce and hard to perceive (see further 4.2 below).

Furthermore, there are counter-examples to the change proposed by Melchert (cf. Kloekhorst 2008, 69-70, 602). The clearest of these is the PIE enclitic particle ${ }^{*}=k^{w} e$, which is directly continued in Hitt. $=k k u$ and contained

27 Hittite also attests a verb neku- 'get dark; become evening' derived from the same root (<

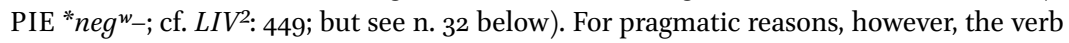
occurs in Hittite (and presumably, in PIE/PA) only in the 3SG (NPST.ACT nekuzzi; MID nekutta), where */t/-initial inflectional endings would have devoiced the root-final stop; it therefore cannot provide an analogical source for the Hittite non-geminate (< voiced) stop (cf. Melchert 1994, 18). 
in the modal complementizer takku 'if' $\left(<{ }^{*} t o ́-k^{w} e\right)$ and in the negative rhetorical question marker nekku $\left(<{ }^{*} n e ́-k^{w} e\right) .{ }^{28}$ The Hittite geminate stop in these forms points to a pre-Hittite voiceless stop, which is inconsistent with the hypothesis that word-medial PIE ${ }^{*} k^{w}$ became ${ }^{*} g^{w}$ in PA.

Finally, to these issues may be added the dwindling empirical support for PIE ${ }^{*} k^{w}>$ PA ${ }^{*} g^{w}$ in other phonological environments. Eichner (2018) has recently suggested that Hitt. šākuwa- 'eye' derives from * $s h_{3}{ }_{0} \bar{k} k^{w}-o$ - (thus modifying Eichner 1973, 82 (cf. Rieken 1999, 59-60) with the generalized * $\bar{o}$-grade

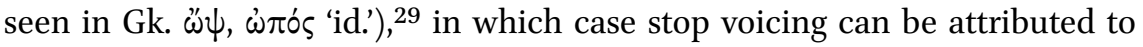
regular PA lenition processes (cf. 2.1 above) ${ }^{30}$ If this attractive proposal is adopted, the only remaining evidence adduced by Melchert $(1994,61)$ for the change is Hitt tarwiške- 'dance', the imperfective to tarku- 'id.' (< PIE *terk ${ }_{-}^{w_{-} \text {; } c f .}$ Kloekhorst 2008, 842-844), with unexpected deocclusion of the labiovelar stop with respect to its base form; while a full treatment of this problem is beyond the scope of this paper, tarwiške- alone is in any case a very limited basis on which to reconstruct a general word-medial change PIE ${ }^{*} k^{w}>\mathrm{PA}^{*} g^{w} \cdot{ }^{31}$

In view of these problems, the voicing process hypothesized by Melchert does not provide a satisfactory explanation of the non-geminate stop in Hitt. nekuz and the other examples in (22). The alternative solution proposed by Kloekhorst (2016) is accordingly treated in 3.2.2 below.

28 For the etymologies, see Kloekhorst (2008, 438-434, 6o1-6o2, 816) (cf. Puhvel 1997, 203205). On the functions of takku and nekku, see Hoffner and Melchert (2008, 345-346, 419-423); on their phonology, I follow Garrett apud Melchert $(1994,184)$ in assuming that post-tonic word-final */e/ was first reduced to *[ə] and then rounded to [u] by the preceding ${ }^{*}\left[\mathrm{k}^{\mathrm{w}}\right]$, which was thus intervocalic when STVL took place in pre-Hittite and remains so in Hittite (contra Kloekhorst 2008, 24-25, 615; 2016, 221).

29 Derivation of Hittite šăkuwa- from an *s-initial pre-form such as * ${ }^{*}{ }^{*} k^{w_{-}-o-}$ (Čop 1955, 69; cf. Melchert 1994, 61, Kloekhorst 2008, 704-706) or its "vrddhi-derivative" * sốkw-o- (Michael Weiss, p.c.) fails to account for its Anatolian cognates CLuw. tāwa/i- 'eye' and Lyc. tewe'id.. How exactly such Hittite $\check{s} \sim$ Luw./Lyc. $t$ correspondences are to be explained is difficult and much disputed (see Oettinger 2009, Byrd 2012, and most recently Cohen and Hyllested 2018 on the problem), but one thing that is clear is that none of these correspondence sets can be traced back to a PIE etymon with an invariant prevocalic word-initial ${ }^{*} s$ - in its inflectional paradigm.

30 A further implication of Eichner's (2018) proposal is that it eliminates the last of the compelling evidence outside of ablauting hi-verb paradigms presented by Kloekhorst (2008, 65,$98 ; 2014,553-559$ ) for lenition of preceding voiceless stops by PA *ó (cf. 3.1 above). In view of clear counter-evidence to lenition in this environment-e.g., (5a), (14a), and (14c) above-it is much more likely that the singleton : geminate stop alternation in ablauting hi-verbs like aki 'dies': akkanzi 'they die' is due to interparadigmatic analogy, as argued by Melchert (2012).

31 See Kloekhorst $(2008,842-844)$ for a possible alternative solution. 


\subsubsection{Unexpected Hittite $-k u$ - for $-k k u$ - per Kloekhorst 2016}

Kloekhorst's (2016) solution shares with Melchert's $(1994,61)$ the assumption that the problematic Hittite words in (22) reflect what is-viewed in traditional terms - a prehistoric unassimilated cluster * $\left[-\mathrm{g}^{\mathrm{w}(\mathrm{h})} \mathrm{t}-\right]$ in which Hittite $-k u-\left(\left[\mathrm{k}^{\mathrm{w}}\right]\right)$ continues the cluster-initial voiced stop. However, Kloekhorst's proposal differs significantly in that he assumes this cluster is not a PA innovation but instead a conservative feature; in his view, the regressive voicing assimilation process in (11) did not apply in PIE (as in Hittite), but was rather an innovation of Proto-Nuclear-Indo-European (PNIE), the common ancestor of the non-Anatolian Indo-European languages (contra Mayrhofer 1986, 110 et al.; but cf. Eichner 2015, 13-14).

This hypothesis offers a possible account of examples like (22a) and (22b) above in which an underlying root-final voiced stop can be securely inferred on comparative and/or language-internal grounds. The prehistory of Hitt. eku/ $a k u$ - 'drink' — and the comparative evidence for root-final */gwh/ (< PIE * $h_{1} e g^{w h_{-}}$) — was discussed already in 2.1 above. Similarly, the PIE word for 'night' is standardly analyzed as a *t-stem formed from the root * $n e g^{w_{-}}$'get dark' (cf. $N I L: 5^{\circ} 5^{-513)} \cdot{ }^{32}$ In a phonological system that lacks voicing assimilation, one would therefore expect derivations like (24), where the underlying voicing of the root-final stop is preserved before voiceless */t/; these outputs would then correctly yield the attested Hittite forms with singleton stop:

(24) a. PIE */négw-t-s $/ \rightarrow^{*}[$ négwts $]>$ Hitt. nekuz

b. PIE */ $\mathrm{h}_{1} \mathrm{eg}^{\mathrm{wh}}-\mathrm{t} / \rightarrow^{*}\left[\mathrm{~h}_{1} \mathrm{ég}^{\mathrm{w}(\mathrm{h})} \mathrm{t}\right]>$ Hitt. ekutta

c. PIE $* \mathrm{~h}_{1} \mathrm{eg}^{\mathrm{wh}}-\mathrm{tu} / \rightarrow^{*}\left[\mathrm{~h}_{1} \mathrm{ég}^{\mathrm{w}(\mathrm{h})} \mathrm{tu}\right]>$ Hitt. ekuddu

To extend this account to Hitt. sakuttai- in (22d) it would be necessary to stipulate an underlying voiced stop PIE $/ \mathrm{g}^{\mathrm{w}(\mathrm{h})} /$ for which there is no independent evidence, but this analytic move would arguably be justified on the strength of examples like (24).

For Kloekhorst (2016), however, the derivations in (24) have still broader ramifications for the reconstruction of PIE phonology. In his view, the nonoperation of obstruent voicing assimilation in a language in which obstruents

32 The root-final ${ }^{*}{ }^{w h}$ reconstructed for this root by Kloekhorst $(2008,602)$ cannot be maintained in view of the Indo-Iranian evidence, which shows no traces of Bartholomae's Law (e.g., Ved. aktós 'at night' < PIE */ngw-téw-s/; cf. Schindler 1967, 291 n. 1, i.a.). If the analysis developed in section 4 is correct, all of the Hittite evidence for this root is compatible with $* / \mathrm{g}^{\mathrm{w}} /$ or $* / \mathrm{k}^{\mathrm{w}} /$; arguments for reconstructing the former must therefore come from the other IE languages (see NIL, 505-507 n. 1 for discussion). 
contrast for [voice] is "extremely unlikely;" he therefore takes these derivations as evidence that PIE—like Hittite itself (cf. 2.2 above) — did not have contrastive [voice] in obstruents. ${ }^{33}$ He thus rejects the traditional reconstruction of the PIE stop system in (25a) with an opposition between voiceless, voiced, and breathy voiced stops in favor of a much more Hittite-like system in $(25 b)$, where the corresponding stops are voiceless geminates, voiceless "preglottalized," and plain voiceless (cf. Jäntti 2017): ${ }^{34}$

(25) a. Traditional PIE stop system:

\begin{tabular}{llll}
\hline & [-VOICE $]$ & [+VOICE $]$ & [+VOICE, +S.G. $]$ \\
\hline LABIAL & $* / \mathrm{p} /$ & $* / \mathrm{b} /$ & $* / \mathrm{b}^{\mathrm{h}} /$ \\
CORONAL & $* / \mathrm{t} /$ & $* / \mathrm{d} /$ & $* / \mathrm{d}^{\mathrm{h}} /$ \\
DORSAL & $* / \hat{\mathrm{k}} \mathrm{k} \mathrm{k}^{\mathrm{w}} /$ & $* / \hat{\mathrm{g} g ~ g} /$ & $* / \hat{g}^{\mathrm{h}} \mathrm{g}^{\mathrm{h}} \mathrm{g}^{\mathrm{wh}} /$
\end{tabular}

b. PIE stop system per Kloekhorst 2016:

\begin{tabular}{|c|c|c|c|}
\hline & {$[+\mathbf{L O N G}]$} & [-LONG, +“PGL”] & {$[-\mathbf{L O N G}]$} \\
\hline LABIAL & $* / p: /$ & $* /{ }^{2} \mathrm{p} /$ & $* / \mathrm{p} /$ \\
\hline CORONAL & $*|\mathrm{t}:|$ & $*\left|{ }^{2} \mathrm{t}\right|$ & $* / t /$ \\
\hline DORSAL & $* / \hat{\mathrm{k}}_{\mathrm{a}} \mathrm{k}_{\mathrm{a}} \mathrm{k}^{\mathrm{w}_{\mathrm{a}}} /$ & 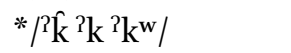 & $* / \hat{\mathrm{k} \mathrm{k} \mathrm{k}} \mathrm{w} /$ \\
\hline
\end{tabular}

This radical revision of the PIE stop system - first proposed by Kortlandt (2010) (cf. Beekes and de Vaan 2011, 119-136) — would have significant consequences for how STVL is understood. Under this view, STVL never took place: the PIE system was maintained into PA and preserved essentially intact in Hit-

33 This argumentation itself is highly questionable (cf. Simon 2017). Gordon $(2016,128)$ finds that just fourteen languages out of a genetically and geographically diversified 100 language sample have voicing assimilation processes. Several specific languages with contrastive obstruent voicing but without voicing assimilation (Kannada, Tulu, Berber) are also noted by Wetzels and Mascaró (2001) in their discussion of the typology of voicing assimilation and related processes.

34 The term "preglottalized" ("PGL") is problematic, as its usage is highly variable (see Clements and Osu 2002); Kloekhorst (2016) offers no explicit definition of the term, but it appears that in his view the essential property of these stops, detectable in Anatolian and elsewhere, is that they tend to cause lengthening of a preceding vowel (e.g., Winter's Law in Balto-Slavic; Lachmann's Law in Latin). 
tite. ${ }^{35}$ Instead, it is PNIE that has innovated, having developed the familiar system in (25a) with contrastive voice-and along with it, regressive voicing assimilation - by a set of leniting changes that amount to a kind of "reverse Sturtevant's Law:" geminate stops underwent degemination; non-geminate stops became voiced (for the precise details of this proposal, see Kloekhorst 2016; cf. Jäntti 2017).

In what follows, however, I will argue that the Hittite forms in (22) taken by Kloekhorst as support for his proposal are in fact better explained under the traditional reconstruction of the PIE stop system. In the next section (4), an alternative account of these seemingly problematic forms is developed. I present evidence showing that Hittite $-k u-\left(\left[\mathrm{k}^{\mathrm{w}}\right]\right)$ rather than $-k k u-\left(\left[\mathrm{k}^{\mathrm{w}} \mathrm{]}\right]\right)$ is the regular outcome of the first voiceless stop in a prehistoric cluster ${ }^{*}\left[k^{\mathrm{w}} \mathrm{t}\right]$, thus obviating the need to reconstruct an unassimilated cluster ${ }^{*}\left[-\mathrm{g}^{\mathrm{w}(\mathrm{h})} \mathrm{t}-\right]$ as per Kloekhorst 2016 (or Melchert 1994; cf. 3.2.1 above).

This section explores the possibility that STVL was not-as previously assumed - a context-free (i.e., across-the-board) phenomenon, applying to all stops that were phonetically voiceless/voiced at the time of its operation. While viewing STVL as a regular sound change of course opens up this possibility (cf. 2.2 above), it apparently has not been considered in previous treatments of STVL. For instance, the assumption that Hittite word-medial non-geminate obstruents must continue pre-Hittite voiced obstruents is clearly implicit in Melchert's (1994) attempt to explain forms like nekuz in (22) via PA wordmedial voicing of ${ }^{*} k^{w}$ (cf. 3.2.1 above). I begin from the opposite assumption here-viz., that STVL was a conditioned change. The major hypothesis advanced in this section is that the apparent exceptions to STVL in (22) are in fact phonologically regular once the domain of STVL is properly constrained. The specific restriction on STVL relevant to these forms is introduced in 4.1, along with new empirical evidence in support of the proposed conditioning environment.

35 See Kloekhorst (2016) for the full proposal; note, however, that in 5.2 below I explicitly reject a number of his individual claims (see esp. nn. 69-70) and more broadly argue against his reconstruction of the PIE stop system. 


\subsection{The phonological domain of Sturtevant's Law}

In view of the problematic forms in (22), I propose that, when immediately preceding another stop, the regular outcome of a pre-Hittite word-medial voiceless stop via STVL was a Hittite non-geminate stop. Under this view (formalized phonologically in 4.3 below), voiceless stops before stops did not undergo the historical lengthening process that affected other word-medial voiceless obstruents as part of STVL; their reflexes were thus identical to those of voiced stops before stops. The proposed developments are represented schematically in (26), where the dotted lines represent the historical changes before stops and the solid lines the changes elsewhere (cf. (12) above):

\section{Changes via restricted STURTEVANT's LAW}

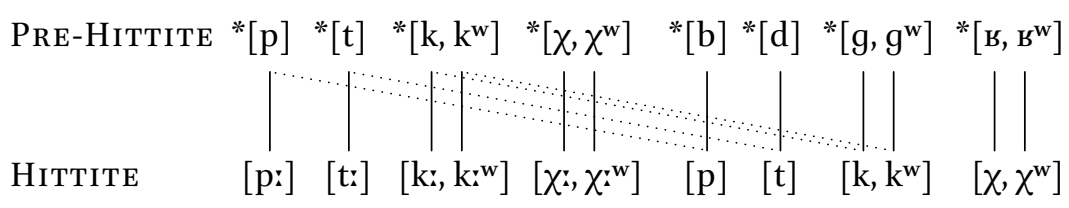

Imposing this restriction on the domain of STVL straightforwardly accounts for all of the problematic examples in (22), repeated in (27) below:

(27) a. PIE *né[ $\left[\mathrm{k}^{\mathrm{w}}-\mathrm{t}\right]-\mathrm{s}>$ Hitt. nekuz (mehur) '(time) of evening' GEN.SG

b. PIE * $h_{1} e$ [ $\left[\mathrm{k}^{\mathrm{w}}-\mathrm{t}\right]>$ Hitt. ekutta 'drank' 3SG.PST.ACT

c. PIE ${ }^{*} s(o)\left[\mathrm{k}^{\mathrm{w} t}\right] h_{2}$-ối > Hitt. šakuttai / šakutāe 'thighs' N.NOM/ACC.PL

In each case, this approach derives the Hittite form with non-geminate stop from its traditionally reconstructed PIE surface form with a voiceless stopstop cluster that is expected in a language with regressive voicing assimilation. Note that this is especially advantageous for $(27 \mathrm{c})$, where there is comparative support (from Ved. sákthi- 'thigh') only for reconstructing a ${ }^{*}\left[\mathrm{k}^{\mathrm{w} t}\right]$ cluster in which the labiovelar stop is morpheme-internal; there is therefore no independent motivation (e.g., from alternations) for assuming that this stop was underlyingly voiced, as would be necessary under Kloekhorst's (2016) analysis to explain its non-geminate outcome (cf. 3.2.2 above).

More generally, this approach makes a strong empirical prediction about the orthographic representation of etymological voiceless stop-stop clusters into 
Hittite-namely, that the cluster-initial stop should never be spelled geminate. This prediction is borne out not only by the data in (27) but also by the histori$\mathrm{cal}^{*}\left[-\mathrm{tk}^{(\mathrm{w})}\right.$ - $]$ clusters in $(28)$; these clusters have not previously been considered in this context, but in fact show consistent singleton spellings of the clusterinitial * $[t]$, never geminate spellings like (29) which might be expected under the more traditional interpretation of STVL: ${ }^{36}$

$$
\begin{aligned}
& \text { a. PIE *(we/o)-tkw- > Hitt. }\langle w a-a t-k u-z i\rangle,\langle w a-a t-k u-u t-t a\rangle\rangle^{\prime} \text { leaps/leapt' } \\
& \text { 3SG.NPST/PST.ACT }
\end{aligned}
$$

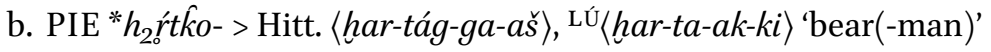

$$
\begin{aligned}
& \text { (= (17a) above) }
\end{aligned}
$$

(29) a. $\times\langle w a-a t-t u-u k-z i\rangle, \times\langle w a-a t-t u-u k-t a\rangle$

b. ${ }^{\times}\langle$har-at-tág-ga-aš $\rangle, \times\langle h a r-a t-t a-a k-k i\rangle$

It might be argued that the absence of geminate $-t t-\left(\left[t_{2}\right]\right)$ spellings like (29) for the relatively well-attested words in $(28)$ is due to some kind of orthographic constraint against spelling adjacent geminates. However, the spelling in (30a) below shows that it is orthographically possible in Hittite to express the geminate quality of a consonant before another consonant, and ( $30 \mathrm{ob})$ that this is the case even in a triconsonantal cluster and even when the following consonant is also a geminate. The spelling in (3oc) demonstrates that an empty vowel can be used after a $C V C$ sign to facilitate geminate spelling of a following consonant, as would be the case in $(29 \mathrm{~b})$. Finally, (3od) provides a nearly exact orthographic parallel for the unattested spelling in (29a): a geminate consonant $([\mathrm{r}:])$ is spelled geminate before a labialized obstruent $\left(\left[\chi^{\mathrm{w}_{\mathrm{i}}}\right]\right)$, an environment in which it is relatively easy to represent faithfully due to the possibility of spelling the labialized consonant $\langle u C\rangle .{ }^{37}$

36 For the etymology in (28a), see $L I V^{2}, 620-621$ with references (cf. Kloekhorst 2008, 989990); its phonology is discussed further below.

37 See Kloekhorst $(2008,838-839)$ for attestations of the verb and its derivation from PIE ${ }^{*} t e r h_{2}-u-$. The geminate quality of [r:] in (3od) is supported by numerous spellings, although no satisfactory explanation has been previously proposed $\left(<{ }^{*} r\right)$. Craig Melchert (p.c.) suggests the following stepwise historical scenario: (i) the regular outcome of PIE

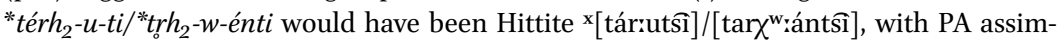
ilation ${ }^{*} V R H V>{ }^{*} V R R V$ (Melchert 1994, 79-81) bleeding fusion of ${ }^{*} h_{2}$ with ${ }^{*} w$ (cf. n. 4 above); (ii) the * $[\mathrm{r}:]$ in the strong stem was analogically leveled into the weak stem; (iii) the weak stem was generalized throughout the paradigm prior to the operation of STVL. 
(30) a. 〈ša-ak-ka $\left.a_{4}-a h-h i\right\rangle$ 'I know' 1SG.NPST.ACT

b. $\langle p a-a h-h a-a s ̌-s ̌ a-n u-u t\rangle$ 'protect!' 2SG.IMP.ACT

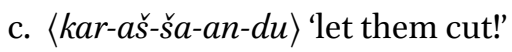
3PL.IMP.ACT

d. $\langle$ tar-ru-uh-zi $\rangle,\langle$ tar-ru-uh-ha-an-zi $\rangle$ 'conquer $/ \mathrm{s}$ ' 3SG/PL.NPST.ACT

The spellings in (30) thus argue strongly that the consistent singleton $-t$ - in the examples in (28) should be taken seriously-i.e., as the orthographic representation of Hittite [t]. This result is significant, in part because these examples provide a testing ground for comparing the hypothesis developed in this section with that of Kloekhorst (2016).

In order to explain the non-geminate [t] in these forms, Kloekhorst would need to posit original (breathy) voiced stops in these items, which were then subject to voicing assimilation in the NIE languages. For PIE 'bear' in (28b) as was the case for 'thigh' in (27c) above-there is no independent motivation for this assumption, since the relevant stop occurs only morpheme-internally (i.e., within the nominal root ${ }^{*} h_{2} r t \hat{k} o-$ ), and its only unambiguous NIE reflexes

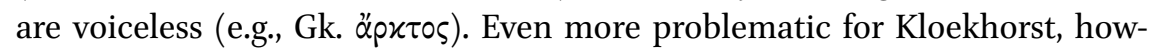
ever, is (28a). A connection between Hitt. watku- 'leap' and the Sanskrit root tak- (in, e.g., INF Ved. tákave 'for rushing; to charge') has been accepted at least since Čop $(1955,69)$ (cf. Kloekhorst 2008, 989-99o). This connection requires reconstructing PIE ${ }^{*} t e k^{w}$ - with a root-initial voiceless stop ${ }^{*} / t / ;^{38}$ it is therefore impossible to extend to Hitt. watku- the type of explanation proposed by Kloekhorst (2016) for nekuz and ekutta. In contrast, both of the examples in (28) are consistent with the restricted formulation of STVL proposed above: the relevant stop ${ }^{*} t$ occurs immediately before another stop $\left({ }^{*} k^{w},{ }^{*} \hat{k}\right)$ and so is predicted to develop into the non-geminate stop that is found in Hittite. Yet is it possible that there is other counter-evidence to this hypothesis?

The only potential counter-examples (to my knowledge) to STVL in its restricted form are verbal forms like those in (31) - i.e., Hittite geminate stops that reflect PIE root-final voiceless stops at an inflectional boundary:

38 Other derivatives of this PIE root include OIr. teichid 'flee', Lith. tekù 'flee; run', and OCS tekco 'id.' (see $L I V^{2}$ : 620-621). 
(31) a. Hitt. $\langle a p-p a-a t-t a-a t\rangle$ '(s)he was taken' 3SG.PST.MID

b. Hitt. $\langle s u$-up-pa-at-ta $\rangle$ 'sleeps'

$\left(<\mathrm{PIE} * h_{1} e p-\right)$

c. Hitt. $\langle l u-u k-k a t-t a\rangle$ 'dawns; gets light'

It is uncertain, however, how the forms in (31) should be interpreted phonologically. The primary issue is whether they contain a real geminate-geminate stop cluster or else a sequence of geminate stops separated by a real $a$-voweli.e., [p:-t:] or [p:-at:] in (31a-b), [k:-t:] or [ki-at:] in (31c). Both interpretations are morphologically viable, since Hittite has both -tta(t) and "renewed" -atta as allomorphs of the 3SG.MID ending. ${ }^{39}$ If the latter is correct, the forms in (31) are unproblematic: the root-final geminate stop is prevocalic and thus the expected outcome of a prehistoric voiceless stop via STVL.

Yet if instead it is the case that the geminate clusters are real, an alternative explanation is available - namely, that the historically unexpected geminate is the result of intra- or interparadigmatic leveling. Each of Hittite verbal roots in (31) is attested in other morphological contexts in which the inherited root-final voiceless stop would have been subject to gemination via STVL, e.g.: 3PL.NPST.MID Hitt. appantati 'were taken' (< (virtual) PIE * $h_{1} p$-ñto); ${ }^{40}$ 3SG.N PST.MID Hitt. šsuppari 'sleeps' (<PIE *sup-ór); 3SG.PST.ACT Hitt. lukkešta 'became light' $\left(<\mathrm{PIE} * l(e) u k\right.$-éh $\left.h_{1} s-t\right)$. The fact that these historically unexpected geminates occur at a transparent, productive morpheme boundary makes such an analogical development relatively trivial. In this respect, moreover, they differ from the putatively aberrant non-geminate stops in $(27 \mathrm{c})$ and $(28 \mathrm{a}-\mathrm{b})$ : the relevant stop in sakuttai-, watku-, and hartagga- is morpheme-internal and thus confined to this pre-stop context. ${ }^{41}$ Because these non-geminate stops do not occur in any other environment, no such analogical explanation is viable; rather, they must be the phonologically regular historical outcome of voiceless stops before another stop.

Of these two possibilities for the forms in (31), I view the "sequential" interpretations [p:-at:] and [ki-at:] as likelier. For (31c), there is independent sup-

39 The prehistory of Hitt. -tta $(<\mathrm{PIE}$ * $-t o(r))$ and its tendency to be "renewed" by -atta was first discussed by Watkins (1969, 69, 85-87) (cf. Oettinger 1979, 274-275). Yoshida (2016) argues that -atta is confined to verbal stems in which the first $a$-vowel should be analyzed synchronically as part of the verbal stem (and thus favors the cluster interpretation of the forms in (31); op. cit. 508-510). Against this view, however, see Melchert (to appear). of Hitt. epp/app-, e.g., 3SG.PST eppun < PIE * $h_{1} e$ é-mo, 3 PL.NPST appanzi< PIE * $h_{1} p$-énti.

41 The same reasoning applies also to nekuz in (27a) because the relevant stop-although root-final-occurs only in pre-stop contexts (cf. n. 27 above). 
port for this view: as discussed by Vijūnas (2009, 191-198), the NH reanalysis of the verbal form lukkatta 'dawns' as an adverb (in - $a$ ) meaning 'at dawn; in the morning' formed from a nominal stem lukk-att-is plausible only if the verbal ending had the same phonological shape as the nominal suffix -att- plus the adverbial marker $-a$ (i.e., [-at:a]) ${ }^{42}$ This analysis raises the possibility that prestop geminate stops are categorically absent in Hittite as a result of the failure of historical voiceless stops to lengthen in this environment. This possibility is interesting, especially, for morphemes containing historical voiceless stops that would have undergone gemination in some morphological contexts but not in others-how were such inherited alternations treated synchronically by Hittite speakers? I suggest in 5.3 below that Hittite had a synchronic analogue of STVL-namely, a process whereby underlying geminate stops degeminate before stops (and affricates, due to the later pre-Hittite affrication of 3SG.NPST.ACT * $-t i>-z i)$. It should be emphasized, however, that the historical account of STVL advanced here does not depend on which of the two analyses of the forms in (31) outlined above is correct.

In sum, then, there is no compelling evidence that pre-Hittite voiceless stops developed historically into Hittite geminate stops when immediately preceding another stop. Rather, all available evidence is consistent with the proposed refinement of STVL: inherited voiceless stops underwent gemination in most word-medial environments, but when followed by another stop did not undergo this change. Yet while this conditioning environment is easily stated in phonological terms (see 4.3 below), its phonetic motivation remains to be addressed. This issue is treated in the next section.

\subsection{Motivating the domain of Sturtevant's Law}

Having adduced empirical evidence for a restricted form of STVL in the preceding section, I turn now to its phonological and phonetic underpinnings. Two interrelated questions are of primary interest — on the one hand, why preHittite word-medial voiceless stops developed into Hittite geminate stops, and on the other, why the first stop in voiceless stop-stop clusters did not undergo the same development. I argue below that the differing developments of stops in these environments are phonetically motivated, a function of the relative availability of perceptual cues to consonant duration in each position.

42 The existence of a nominal stem lukk-att-is confirmed by the NH creation of DAT/LOC.SG lukkatti 'id.' On the noun-forming suffix -att- see Hoffner and Melchert (2008, 57). Other temporal adverbs in - $a$ include apiya 'then' and [appaš $]$ iwatta 'in the future' (on the latter, see Rieken 1999, 103). 


\subsubsection{The perceptual basis of Sturtevant's Law}

The starting point for this analysis is the fact-known already to Sturtevant $(1932,12)$ and his contemporaries (see especially Einarsson 1932) - that, typologically, voiceless stops strongly tend to be phonetically longer than voiced stops (see, e.g., Denes 1955; Lisker 1957, 1978; Byrd 1993 and references therein). That is to say, in many languages in which stops contrast phonemically for [voice], there are multiple acoustic (or auditory) features associated with voiceless stops that listeners rely on to distinguish them from voiced stops; ${ }^{43}$ important among these acoustic features—referred to as perceptual "cues" by Wright $(2004,34)^{44}$-is the increased closure duration of voiceless stops vis-à-vis voiced stops, which is also cross-linguistically the most consistent and dependable acoustic cue for stop consonant length (see, e.g., Lahiri and Hankamer 1988; Ham 2001; Ridouane 2003, 26-33; 2007 and references therein). This property has plausibly been taken as a phonetic basis for a type of phonological change whereby a historical phonemic [voice] contrast was reanalyzed as a [long] contrast (Blevins 2004, 175-177), and more specifically, as the basis for STVL (Melchert 1994, 18, Kümmel 2007, 176). Under this view, STVL is a type of "transphonologization" (Hagège and Haudricourt 1978; cf. Hyman 1976, 2013): a phonological contrast is transferred from one of multiple phonetic cues associated with this contrast to another of these cues; the original cue is often then "dephonologized" (as in the case of Hittite [voice]; cf. 2.2 above). I maintain here that this view is essentially correct - against the objections of Kloekhorst (2016) and Jäntti (2017) (discussed further in 5.2 below) — and, moreover, gains further support from its capacity to provide a principled explanation for the exceptional behavior of pre-stop voiceless stops.

One important insight that has emerged from the work of Steriade (1994, 1997), Flemming (1995/2002, 2004), and others is that the availability and robustness of acoustic cues in different contexts plays a significant role in shaping phonological typology. ${ }^{45}$ In particular, there is a strong cross-linguistic tendency for phonological contrasts to be neutralized in contexts in which acoustic cues to their presence are weak or absent. Such synchronic neutralization processes have naturally been analyzed as manifestations of a dispreference for

43 For instance, Lisker (1986) reports 16 different acoustic correlates of the voiceless/voiced opposition for intervocalic stops in American English. For a recent overview of acoustic cues to stop voicing contrasts, see Raphael (2005, 189-193).

44 Specifically, Wright $(2004,36)$ defines a "cue" as "information in the acoustic signal that allows the listener to apprehend the existence of a phonological contrast."

45 See also Zukoff $(2017,219-300)$ on the importance of acoustic cues in licensing the different reduplicative patterns observed in the ancient IE languages. 
contrasts that are poorly cued and, as a result, difficult to perceive. Relatedlybut from a diachronic perspective-Ohala (1981, 1993a,b), Blevins (2004), and others (especially scholars working in the framework of Evolutionary Phonology) have demonstrated that many sound changes are perceptually motivated, occurring in contexts in which the acoustic signal is ambiguous or easily misperceived.

These findings provide the groundwork for the hypothesis pursued here. I propose that the reanalysis of pre-Hittite voiceless stops as Hittite geminate stops was context-dependent, occurring only where the acoustic cues most relevant to the new length contrast (i.e., geminate vs. non-geminate) were robust. Accordingly, it is the distribution of stop closure duration for word-medial voiced and voiceless stops in pre-stop position vs. other phonetic contexts that should be crucial in determining whether or not the reanalysis took place. This property has been investigated experimentally by Luce and Charles-Luce (1985, 1952-1953), who measured the closure duration of voiced and voiceless stops in different phonetic contexts (as produced by native speakers of American English). ${ }^{46}$ Specifically, they compared the closure duration of voiceless stops /p, t, k/ and voiced stops /b, d, g/ in intervocalic position (preceded by / / /, /i/ or /a/ and followed by /a/) and in post-vocalic pre-stop position (preceded by / $\mathrm{r} /$, /i/ or /a/ and followed by /t/) phrase-medially and phrase-finally. Their study finds statistically significant differences in closure duration, voiceless stops being on average longer than voiced stops across all contexts. Notably, however, no significant differences in closure duration were found for phrase-medial stops in pre-stop position, which presents the closest parallel for the wordmedial environment that is relevant for Hittite. The absence of a durational contrast in this environment is evidently related to an asymmetric tendency for stop closure duration to increase before another stop: Luce and CharlesLuce report that both voiced and voiceless stops are significantly longer in this position, but voiced stops undergo greater lengthening and so the durational differences between them and voiceless stops are (at least) reduced. ${ }^{47} \mathrm{~A}$ consequence of these reduced durational differences is that listeners cannot depend

46 As noted by Flemming $(2005,167)$, the number of studies that examine contextual differences in the perception of voicing is unfortunately quite limited (the situation is similar for geminates; see n. 48 below); Luce and Charles-Luce's (1985) study is thus rather exceptional in testing the phonetic correlates of stop voicing in pre-obstruent position. Further research addressing this issue is needed.

47 In the extreme case of $/ \mathrm{g} / \mathrm{vs}$. $/ \mathrm{k} /$, this increase even results in the pre-stop voiced stop being longer than the voiceless stop (see Table III in Luce and Charles-Luce 1985, $195^{2}$ for the data). 
on closure duration to distinguish perceptually between voiced and voiceless stops in this context.

In fact, the contextual variation in closure duration for voiced and voiceless stops observed by Luce and Charles-Luce (1985) has close parallel in that of geminate and non-geminate stops in some languages. ${ }^{48}$ In the Thurgovian dialect of Swiss German, there is a contrast between geminate and nongeminate stops, both of which can occur between sonorants (viz., vowels, glides, liquids, and nasals) as well as word-initially and word-finally; in all positions, closure duration is the only acoustic cue of this contrast (Kraehenman 2001, 110). Of particular interest here are phrase-medial word-final stops, where this contrast is context dependent. When it is immediately followed by a vowel or sonorant consonant within the same prosodic phrase, the contrast between a word-final geminate and non-geminate stop remains robust, the closure duration of the former being significantly longer than the latter. Yet when the following segment is instead an obstruent, this durational contrast effectively disappears-viz., underlying geminate stops do not have significantly longer closure duration than non-geminate stops (op. cit. 129-132).

Two effects conspire to reduce the relative duration of geminate and nongeminate stops in this environment. On the one hand, the duration of nongeminate stops increases, just as was the case in Luce and Charles-Luce's study. On the other hand, geminate stops exhibit decreased duration. The result, once again, is that closure duration ceases to be a reliable cue to this phonemic contrast. This fact is even more striking for these Swiss German stops than for voiceless/voiced stops, since closure duration is the only dependable acoustic cue for this contrast rather than one of multiple cues by which they can be distinguished perceptually; the Swiss German phonemic stop contrast is thus wholly neutralized before phrase-internal obstruents. ${ }^{49}$

The generalization that emerges from these two studies is that in preobstruent contexts closure duration fails to be a reliable acoustic cue for distinguishing between stops that elsewhere can be distinguished perceptually by this property. Further support for this result comes from the typology of gemi-

48 It should be noted, however, that relatively few phonetic studies have measured the properties of non-intervocalic geminates, and fewer still of geminates in word-internal consonant-adjacent contexts; see Ham $\left(2001,15^{-18}\right)$ and Dmitrieva $(2012,8-10)$ for surveys of previous scholarship.

49 This phrase-internal neutralization pattern is phonologically consistent with the absence of geminate obstruents in word-internal obstruent-obstruent clusters (reported by Ehrenhofer 2013, 45); both point to a strong ban against pre- and post-obstruent geminates in Swiss German. 
nate consonants, which show several revealing distributional asymmetries: ${ }^{50}$ (i) geminates are most commonly found in intervocalic position; (ii) some languages have geminates only in intervocalic position (e.g., Ancient Greek, Luiseño, Hopi), but no languages have only non-intervocalic geminates (cf. Thurgood 1993); and (iii) surface non-intervocalic geminates are often actively avoided, either by blocking of gemination (e.g., Hungarian; Pycha 2010) or by degemination (e.g., Maltese, Polish; Borg 1997, Pająk 2009). ${ }^{51}$ Pająk (2013, 3-4) argues that this distribution is perceptually motivated: the durational contrast between geminates and non-geminates is more robustly cued and thus perceptually salient intervocalically than when adjacent to consonants (cf. Dmitrieva 2017,37 ). However, it is likely that cue robustness is not the only factor at work in shaping this distribution. Dmitrieva's (2012, 132-133; 2018, 53-54, 60) experimental studies of geminate consonant perception in speakers of American English, Russian, and Italian find that they are significantly less likely to perceive a consonant as long in pre-consonantal position than in intervocalic position even when it has the same closure duration. If Dmitrieva's findings reflect a perceptual bias against pre-consonantal [+long] consonants (cf. Dmitrieva 2011), this bias may also influence geminate typology, either inhibiting new geminates from arising in this context or facilitating the reduction of existing geminates to non-geminates.

\subsubsection{Sturtevant's Law as contextual reanalysis}

It is now possible to evaluate the typological plausibility of the proposal for STVL advanced above. In a sense, this proposal has two components. The first is that, while pre-Hittite speakers generally perceived a durational contrast between (longer) voiceless and (shorter) voiceless stops, they did not perceive this contrast in pre-obstruent contexts; thus when stop duration came to be phonologized as part of STVL, these durationally indistinct stops were assigned to the same phonological category. This hypothesis is strongly supported by the evidence discussed above. Since closure duration does not serve as a reliable acoustic cue for the contrast between voiceless stops and voiced stops-nor even for geminate and non-geminate stops-in pre-stop contexts, it would hardly be surprising if listeners failed to apprehend the existence of the contrast and (re-)categorized both stop series in the same way.

50 On the environments in which geminate consonants occur cross-linguistically, see Thurgood (1993), Muller (2001, 204-235), and Pająk (2009, 2013).

$5^{1}$ Geminate avoidance is, of course, an established PIE phenomenon as well; see 5.1 below for discussion. 
The second component of the proposal is that both stop series were reanalyzed as non-geminates in this context. This categorization would be unexpected if the phonological reanalysis proceeded purely on the basis of closure duration, since by this measure pre-stop stops - which likely would have undergone lengthening in this position (as found both by Luce and CharlesLuce 1985 and Kraehenman 2001) — would be most similar to the intervocalic voiceless stops that were ultimately reanalyzed as geminate stops. Yet there are several possible reasons why they were instead categorized as non-geminates (i.e., their actual historical outcome, as demonstrated in 4.1 above). One factor that may have played a role was the perceptual bias discussed above, which would favor the acquisition of [-long] consonants in pre-consonantal contexts, where [+long] consonants are more difficult to perceive and therefore also to learn. Note, too, that there is some additional experimental evidence to suggest that the difficulty of discriminating [+long] from [-long] stops in particular increases as the sonority of the following consonant decreases (Dmitrieva 2015; see 4.3.2 below for further discussion); if this is the case, then geminate stops in pre-stop contexts would be especially dispreferred.

In addition, the categorization of these durationally indistinct pre-stop stops may have been influenced by their similarities to prototypical voiced stops along other (i.e., non-durational) acoustic dimensions. Two potentially relevant acoustic properties of stops are their voice onset time (VOT; positive values correlate with aspiration) and their closure release burst; cross-linguistically, these properties contain important cues to stop voicing contrasts (see, e.g., Raphael 2005, 189-193) and, crucially, are often or even consistently absent in pre-stop environments. Voiceless stops are typically distinguished from voiced stops by their increased VOT-i.e., a longer interval between their closure release and the onset of voicing in a following vowel or sonorant (Lisker and Abramson 1964, 1970, i.a.). Yet since VOT can only be observed when a [+sonorant] segment follows, it is unavailable in pre-obstruent position. This point could be significant, since there is experimental evidence to suggest that in the absence of this cue listeners may perceive voiceless stops as voiced stops (Lotz et al. 1960, Reeds and Wang 1961). ${ }^{52}$ In a similar vein, the release burst of voice-

$5^{2}$ In the study of Lotz et al. (1960), the relevant stops-which were voiceless and unaspirated, having been extracted from word-initial $s$-stop clusters by deleting the initial sibilant - were categorized as "voiced" ([+voice]) by speakers of American English, but when presented to Spanish or Hungarian speakers, were classified as "voiceless" ([-voice]). This result reflects different category boundaries in English vs. Spanish and Hungarian for stop voicing: in English [+voice] word-initial aspirated stops with long-lag (i.e., large positive VOT) contrast with short-lag (small positive VOT) [-voice] unaspirated stops, whereas in 
less stops is characterized by greater spectral energy at higher frequencies than that of voiced stops (see Chodroff and Wilson 2014 with references). However, it is often the case that stops are unreleased (i.e., lack an audible release burst) when preceding another stop. ${ }^{53}$ Once again, perception experiments show that listeners tend to identify stops that have a weak or missing release burst as voiced (Wang 1959, Chodroff and Wilson 2014). These facts recommend the following scenario: in the absence of these secondary acoustic cues, pre-stop voiceless stops (and trivially, voiced stops) were more perceptually similar to voiced stops than voiceless stops and, having thus been identified with the voiced (> non-geminate) set, were subject to the same analysis as voiced stops in contexts where closure duration was more robustly cued.

\subsubsection{On the perceptual conditions for gemination}

Before proceeding, there are three environments in which gemination did occur that merit further discussion within the context of the cue-based approach developed above: (i) post-obstruent voiceless stops; (ii) voiceless stops before /s/; and (iii) voiceless fricatives before stops (for the evidence see (16-17) and (21) above). Concerning the first two environments, the most important point is that, while neither has the ideal acoustic conditions for this development, both are more perceptually favorable to it than the pre-stop context in which it did not take place; in other words, the cue-based approach does not make any perverse predictions about the (non-)emergence of Hittite geminate obstruents in these environments. Thurgovian Swiss German provides evidence that stop length contrasts can still be discriminated in post-stop phrase-internal position (unlike in pre-stop position, as discussed above), geminate stops having significantly greater closure duration than non-geminates in this environment (Kraehenman and Lahiri 2008). ${ }^{54}$ Moreover, in post-stop con-

Spanish and Hungarian short-lag [-voice] stops contrast with lead-voicing (negative VOT) [+voice] stops in this position. The absence of closure voicing thus triggers voiceless percepts for the latter group (cf. Raphael 2005, 190).

53 In American English, for instance, stops are "generally" unreleased before another stop (e.g., Ladefoged and Johnson 2011, 6o-61); this description is consistent with the results of Randolph's $(1989,116)$ corpus study of read speech, which finds that nearly $80 \%$ of stops were unreleased when followed by an oral or nasal stop (see the data in Figure 4.7b).

54 More broadly, Dmitrieva (2015) finds that closure duration is more perceptible in syllable onsets than in codas, which could explain the asymmetry in Swiss German between prestop neutralization and post-stop preservation of a length contrast. With respect to Hittite, however, it should be noted that while closure duration is a potential cue of stop voicing contrasts in word-medial post-obstruent stops (see, e.g., Steriade 1997, 6), I am aware of no phonetic studies that specifically address its robustness in this environment. 
texts voiceless stops would be distinguishable from voiced by their increased VOT and their higher energy/frequency burst spectra, which might facilitate their identification with the voiceless (> geminate) set.

The situation differs slightly in the second environment, since stop voicing contrasts were neutralized before /s/ in Hittite: all stops were voiceless due to the regressive assimilation process in (11) above. The only issue, then, is the categorization problem-i.e., why these voiceless stops were reanalyzed as geminates. Once again, this development does not falsify the predictions of the cue-based account: any perceptual bias against pre-consonantal [+long] stops would likely have been weaker in the pre-/s/ context than the pre-stop context because /s/, a fricative, is more sonorous than a stop (Dmitrieva 2015; see above). Furthermore, while VOT would not be available as a secondary cue for stops in this context, these stops might still have had a release burst, which would have made them more perceptually similar to other voiceless stops.

The last case that requires special discussion is the development of fricatives in pre-stop contexts. Just as is the case for stops, voiceless fricatives tend to be phonetically longer (in terms of frication duration, the partial closure involved in the production of a fricative) than voiced fricatives crosslinguistically (Denes 1955, Cole and Cooper 1975, i.a.), which explains why preHittite voiceless dorsal fricatives generally pattern with voiceless stops with respect to STVL, undergoing gemination in the same set of contexts. Voiceless fricatives, however, also geminate before a stop. This differing behavior suggests that in pre-Hittite the durational contrast between voiceless and voiced fricatives — unlike between voiced and voiceless stops (cf. 4.2.1 above)—was maintained in pre-stop contexts. Typological support for this possibility comes from Pająk's (2013) experimental study, which measured the duration of voiceless and voiced fricatives $(/ \mathrm{s} / \mathrm{vs}$. $/ \mathrm{z} /$, as produced by speakers of Moroccan Arabic) in different phonetic contexts, including before a word-medial stop $(/ t /)$. She found that fricatives show the same lengthening effect as stops when preceding a stop, but in contrast to stops, voiceless fricatives are consistently still longer than voiced fricatives in this environment..$^{55}$ Supposing a similar situation held in pre-Hittite, it follows that the longer voiceless fricatives (i.e., $\left.{ }^{*}|\chi|,{ }^{*} \mid \chi^{\mathrm{w}} /\right)$ would be unconditionally reanalyzed as geminates $\left(|\chi:|, \mid \chi^{\mathrm{w}} \mathrm{w} /\right){ }^{56}$

55 See Pająk $(2013,7-10)$ with data in Figure 1. I am not aware of any other phonetic studies that address this issue.

56 As discussed in section 1 , pre-Hittite $* / \mathrm{s} /$ and $* / \mathrm{h} / \mathrm{did}$ not undergo this reanalysis because they lacked phonemically contrastive [+voice] counterparts. 


\subsubsection{Summary - the phonetic motivation for Sturtevant's Law}

It was shown in 4.2.1-4.2.3 that the phonological restriction on STVL proposed in 4.1 to account for empirical facts about the development of Hittite wordmedial obstruents also has a phonetic basis: the environments in which the pre-Hittite voicing contrast was reanalyzed as a length contrast are precisely those in which the major acoustic correlate of the new contrast, closure duration, was perceptually salient. Conversely, for stops in pre-stop contexts this contrast was weakly cued and, as a result, diachronically neutralized such that historically voiceless and voiced stops developed into non-geminate stops.

\subsection{Formalizing Sturtevant's Law}

The aim of this section is to develop a formal account of the conditions under which pre-Hittite voiceless and voiced obstruents developed into Hittite geminate and non-geminate voiceless obstruents-i.e., the set of historical developments that together constitute STVL. Specifically, I propose a synchronic analysis of the phonological grammar that, in my view, constitutes the likeliest immediate diachronic precursor of the attested Hittite situation in which STVL has taken place (and which is effectively identical to what Melchert (1994, 21) posits for PA itself). Descriptively, the most relevant phonological characteristics of the proposed pre-Hittite stage are stated in $(32)$ :

(32) a. Obstruents were (still) contrastively specified for [ \pm voice].

b. Voiceless obstruents were subject to allophonic gemination in all wordmedial environments except for voiceless stops before stops.

The analysis developed here is framed in terms of Optimality Theory (OT; Prince and Smolensky 1993/2004). The basic gemination pattern is analyzed in 4.3.1; I then proceed in 4.3.2 to the exceptional non-gemination of pre-stop voiceless stops and show that it can be neatly captured in OT as a blocking effect.

\subsubsection{Deriving gemination of voiceless obstruents}

At the core of STVL is the gemination of word-medial voiceless obstruents. To account for this pattern, I posit the markedness constraint in (33), which militates against short voiceless obstruents (here symbolized $\mathrm{T}):^{57}$

57 To be precise, $\mathrm{T}$ stands for [-voice, -sonorant, -strident, +consonantal] segments (cf. section 1 above). In featural terms, the constraint in (33) is thus equivalent to * [-voice, -sonorant, -strident, +consonantal, -long]). 
(33) ${ }^{*}[-$ long $] /$ T: Assign a violation $\left(^{*}\right)$ for each [-long] voiceless non-sibilant consonantal obstruent in the output.

In the general case, the effect of * [-long]/T is that input voiceless stops undergo phonological repair, two minimal strategies for which are available: (i) lengthening, which would be a type of CUE ENHANCEMENT (Keyser and Stevens 2001, 2006), reinforcing an existing phonetic property that distinguishes voiceless obstruents from shorter voiced obstruents (see further 5.2 below); 58 or (ii) voicing, which would neutralize the underlying contrast between voiceless and voiced stops. These two repair strategies conflict, respectively, with the faithfulness constraints in (34a) and (38b), which require that input and output consonants have the same specification for length and voicing.

(34) a. ID(ENT)-C[long]: Corresponding input and output consonants must have the same specification for [long].

b. ID(ENT)-C[voi(ce)]/_[+son]: A consonant preceding a [+sonorant] segment in the output must have the same specification for [voice] as its input correspondent.

The constraint in (34b) is a context-specific version of IDENT-C[voice] defined in $(38 \mathrm{~b})$ below; it requires that an output consonant and its input correspondent have the same [voice] specification when it occurs in a position in which voicing cues are highly perceptible — namely, in pre-sonorant position (cf. Steriade 1997) - as expected under the cue-based approach adopted in 4.2.1 above. ${ }^{59}$ The need for (34b) beside generic IDENT-C[voice] will become clear in the discussion of assimilation below.

58 It should be noted that *[-long]/T would also drive lengthening of voiceless obstruents in word-initial and word-final position (if the latter exist; cf. $n$. 68 below). While I have refrained in this paper from making any explicit claim about the Hittite outcomes of non-word medial voiceless obstruents, if it is indeed the case that they are [-long] (cf. $n .77$ below), this could be accounted for by positing additional highly-ranked positional markedness constraints *GEMP/\#_and/or *GEMP/_\# ("No word-initial/final geminate stops") that would block gemination in the relevant context(s). Both constraints are phonetically grounded and typologically well-supported (cf. Pająk 20og; Dmitrieva 2012).

59 The effect of (34b) is effectively identical to IdENT-C/OnSET[voice] ("An output consonant in a syllable onset must have the same specification for [voice] as its input correspondent;" cf. Beckman 1998, 22, Lombardi 1999, 270) in a syllable-based analysis. 
The fact that voiceless stops underwent lengthening in pre-Hittite requires that *[-long]/T in (33), the constraint driving lengthening, dominates ID-C [long] in (34a), which penalizes such lengthening. This pattern also requires that that *[-long]/T is dominated by ID-C[voi] /_[+son] in (34b), which militates against the alternative repair strategy for violation of * $[-$ long $] / T$, viz., voicing. The constraint ranking necessary to derive the correct outcome is stated in (35), and demonstrated in the tableau in (36) with the Hittite verb epp/app'take':

（35） ID-C[voi]/_[+son], *[-long]/T $\gg$ ID-C[long $]$

(36) Pre-Hitt. */hep-m/ $\rightarrow$ *[hép:mo] > Hitt. êppun 'I took' 1SG.PST.ACT

\begin{tabular}{|c|c|c|c|}
\hline /hep-m/ & ID $-\mathrm{C}[\mathrm{voi}] / /[+$ son $]$ & $*[-$ long $] / \mathrm{T}$ & ID-C[long] \\
\hline a. hépm & & $* !$ & \\
\hline b. hép:m & & & * \\
\hline hébm & $* !$ & & \\
\hline
\end{tabular}

The same constraint ranking also correctly predicts non-gemination of voiced stops. * $[-$ long $] / T$ is irrelevant because its length requirement applies only to stops that are voiceless in the output; input voiced stops can thus surface faithfully, as illustrated in (37) with the verb ed/ad- 'eat'. In this tableau, candidate (a) is preferred to $(b-d)$ because the latter gratuitously violate faithfulness constraints.

(37) Pre-Hitt. */hed-m/ $\rightarrow$ *[hédmo $]>$ Hitt. edun 'I ate' 1SG.PST.ACT

\begin{tabular}{|c|c|c|c|}
\hline /hed-m/ & ID-C[voi]/_[+son] & $*[-$ long $] / \mathrm{T}$ & ID-C[long] \\
\hline a. hédm & & & \\
\hline héd:mo & & & $* !$ \\
\hline hét:m & $* !$ & & * \\
\hline hétmo & $* !$ & * & \\
\hline
\end{tabular}


Before turning to the more complicated issue of stop-stop clusters, it will be useful to consider the treatment of pre-Hittite stops before * $s$. No special discussion is needed for underlying voiceless obstruents, which predictably lengthen in accordance with the constraint ranking in (35); the derivation is the same as in (36) above (see (41) below for a full tableau). However, as noted already in 2.2, PIE voiced stops before* $/ \mathrm{s} /$ regularly yield voiceless geminates in Hittite. The simplest explanation for these outcomes is that pre-Hittite stably maintained the regressive obstruent voicing assimilation process that it inherited from PIE alongside its innovative voiceless obstruent gemination process (see further 4.3 and 5 below). The interaction of these synchronic processes resulted in pre-Hittite underlying voiced stops being realized as voiceless geminates before *s (i.e., $/ \mathrm{D} / \rightarrow[\mathrm{T}:] / \_$s).

Two additional constraints are relevant in generating this mapping: AGR [voi] in (38a), which requires adjacent obstruents to have the same voicing specification; and ID-C[voi] in (38b) - the generic version of (34b) abovewhich requires that corresponding input and output consonants have the same voicing specification (regardless of phonological context):

(38) a. AgR(Ee)[voi(ce)]: Assign a violation $\left(^{*}\right)$ for each pair of adjacent [-sonorant] segments that have differing specification for [voice].

b. ID(ENT)-C[voi(ce)]: Corresponding input and output consonants must have the same specification for [voice].

Regressive voicing assimilation emerges when AGR[voi] dominates generic ID$\mathrm{C}[\mathrm{voi}]$ : sequences of obstruents with differing [voice] specification undergo assimilation (violating ID-C[voi]) to satisfy higher-ranked AGR[voi]. The direction of assimilation is then controlled by undominated ID-C[voi $] /[+$ son $]$ : sequences of obstruents assimilate to the [voice] of the final obstruent in the sequence because it stands before a [+sonorant] segment where its voicing specification is protected by higher-ranked ID-C[voi]/_[+son]. Adding this ranking to the established ranking in (35) yields the combined ranking in (39), which is shown in the tableau in (40) to account for devoicing and gemination of voiced obstruents before */s/:

(39) AGR[voi], ID-C[voi]/_[+son], *[-long]/T $\gg$ ID-C[long], ID-C[voi] 
(40) Pre-Hitt. */lag-ské- $\varnothing / \rightarrow$ *[lakssk:é] > Hitt. lakkišk [i] 'incline!' 2SG.IMP.ACT.IPFV

\begin{tabular}{|c|c|c|c|c|c|}
\hline /lag-ské- $\varnothing /$ & Agr[voi] & ID-C[voi $] /[+$ son $]$ & $*[-$ long $] / \mathrm{T}$ & ID-C[long] & ID-C[voi $]$ \\
\hline a. lagské & $* !$ & & * & & \\
\hline b. lagsk:é & $* !$ & & & * & \\
\hline c. lagzgé & & $* !$ & & & $* *$ \\
\hline d. lakské & & & $* ! *$ & & $*$ \\
\hline e. laksk:é & & & $* !$ & $*$ & $*$ \\
\hline f. lakisk:é & & & & $* *$ & $*$ \\
\hline
\end{tabular}

In (40), the faithful candidate (a) and candidate (b) with lengthening of the underlying voiceless stop fatally violate top-ranked AG R[voi] because they contain a sequence of obstruents with opposite voicing specification $\left({ }^{*}[\mathrm{gs}]\right)$. The other candidates avoid this issue by assimilation of [voice]. In candidate (c), the [+voice] feature of the obstruent $* / g /$ is spread progressively at the expense of the $[-$ voice] specification of the following obstruents $* / \mathrm{s} /$ and $* / \mathrm{k} /$; voicing of pre-sonorant $* / \mathrm{k} /$, however, violates undominated ID-C[voi]/_[+son], and candidate $(\mathrm{c})$ is thus ruled out. The remaining three candidates instead exhibit regressive voicing assimilation within the obstruent cluster (in violation of lower-ranked context-free ID-C[voi]); of these, the winning candidate (f) is the one that avoids violating *[-long]/T by lengthening both voiceless stops.

Finally, it may be noted that the derivation of underlying voiceless stops before */s/ is unaffected by adding AG R[voi] to the constraint ranking, since it is satisfied already in the input. The tableau in (41) simply confirms that the combined constraint ranking in (39) produces regular lengthening in such cases:

(41) Pre-Hitt. */hep-ské-mi/ $\rightarrow$ *[hap:sk:émi] > Hitt. appiškimi 'I take’ 1SG.NPST.ACT.IPFV

\begin{tabular}{|c|c|c|c|c|c|}
\hline Input: /hep-ské-mi/ & ID-C[voi $] /[+$ son $]$ & AGR[voi] & {$\left[\begin{array}{l}* \text { long }] / T \\
\end{array}\right.$} & ID-C[long] & ID-C[voi] \\
\hline a. hapskémi & & & $* ! *$ & & \\
\hline b. hapsk:émi & & & $* !$ & * & \\
\hline c. hap:sk:émi & & & & $* *$ & \\
\hline d. habsk:émi & & $* !$ & $*$ & * & $*$ \\
\hline e. habzgémi & $* !$ & & & & $* * *$ \\
\hline
\end{tabular}




\subsubsection{Deriving non-gemination as a blocking effect}

With the core of the analysis in place, it is now possible to turn to stop-stop clusters, where pre-stop voiceless stops exceptionally yield Hittite non-geminate stops. This outcome can be understood naturally as a blocking effect: the gemination process that applied generally to word-medial voiceless obstruents was blocked when a voiceless stop immediately preceded another stop, a context in which — as discussed at length in 4.2.1 above - its closure duration was poorly cued acoustically and thus weakly perceptible. Such phonetic factors provide motivation for positing a markedness constraint against pre-stop geminate stops which, ranked appropriately, functions to block lengthening of pre-stop voiceless stops. Specifically, I propose the constraint in $(42)$ (where P = voiceless stop or affricate, viz. [-continuant, -sonorant]): ${ }^{60}$

(42) *GEMP/_P: Assign a violation (*) for each sequence in which a [+long, -sonorant, -continuant] segment immediately precedes a [-sonorant, -continuant] segment in the output.

Before proceeding with the analysis, the nature of the constraint in (42) merits a brief discussion. (42) belongs to the * GEM family of markedness constraints, which in OT are standardly employed as a means to penalize geminate consonants (cf. Rose 2000). Recent work has argued that *GEM should be decomposed into hierarchical sub-families of constraints targeting, on the one hand, geminates of particular segmental types (Podesva 2002; Kawahara 2007; Kawahara and Pangilinan 2017; Hansen 2012; Hansen and Myers 2017), and on the other, geminates in particular phonological contexts (Pająk 20o9; Dmitrieva 2012). (42) combines these two sub-families, making reference to the segmental properties of the target segment $([-$ continuant $])$ as well as to the context in which it occurs (before a [-continuant] segment). Both restrictions are necessary to account for the Hittite data: if the target segment is [+continuant], it is unaffected by (42), as shown by the (probable) lengthening of pre-Hittite * $\left[\chi^{\mathrm{w}}\right]$ before ${ }^{*}[\mathrm{t}]$ discussed in 3.1; likewise, $(42)$ is irrelevant if the following segment is [+continuant], as evidenced by the lengthening of $*[\mathrm{k}]$ before $*[\mathrm{~s}]$ in $(40)$ and the similar examples cited in 3.1 above.

6o As defined in (42), the constraint will also penalize geminate stops before affricates, which on phonetic grounds should pattern with stops, their initial complete closure exerting the same perceptual effects on the preceding segment. Whether pre-Hittite had affricates in the relevant environment is uncertain, but in synchronic Hittite underlying geminates may precede an affricate at a morpheme boundary (e.g., before 3 SG.NPST.ACT $-z i$ ); see 5.2 below for discussion. 
Yet beyond such empirical considerations, there is reason to believe that the combination of these two constraint sub-families is principled. As noted previously in 4.2.2, Dmitrieva (2015) has found that pre-consonantal geminate stops become more difficult to distinguish from non-geminate stops as the sonority of the following consonant decreases. A potential explanation for this result is offered by a related vein of research, which has focused on the relative perceptibility of different types of intervocalic geminates. Kawahara (2007) and Hansen (2012) argue that intervocalic geminate obstruents are more typologically common than geminate sonorants because their duration is more perceptible, supporting this hypothesis with experimental evidence (see further Kawahara and Pangilinan 2017, 31; Hansen and Myers 2017, 202). Their hypothesis regarding this asymmetry is that sonorant consonants are vowellike, being of similarly high sonority, and so lack clear acoustic boundaries (such as amplitude changes) between them and surrounding vowels, which makes their duration difficult to apprehend accurately in this context. This hypothesis thus implies that what is crucial to the perception of consonant duration is a sonority contrast between the target segment and its context, which would also explain Dmitrieva's result: the duration of low sonority stops is less perceptible when they precede consonants of similarly low sonority. For present purposes, the important take-away from these findings is that perceptually motivated markedness constraints on geminate consonants should make reference both to their segmental properties and their phonological environment, as is the case with (42).

With *GEMP/_P thus established, all that remains to account for the exceptional behavior of voiceless stops in pre-stop contexts is to establish the correct ranking of this constraint. Generating non-lengthening in this context necessitates that *GEMP/_P dominates *[-long]/T and, furthermore, that both AGR[voi] and ID-C[voi]/_[+son] dominate *[-long]/T as well. This ranking is stated in (43) and illustrated in the tableau in (44), where it is shown to make correct predictions for pre-Hittite stop-stop clusters in which the first stop is underlyingly voiceless.

(43) *GEMP/_P, AGR[voi], ID-C[voi $] / \_[+ \text {son }] \gg *[-l o n g] / T \gg$ ID-C[long], ID-C[voi] 


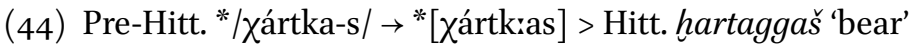
ANIM.NOM.SG

\begin{tabular}{|c|c|c|c|c|c|c|}
\hline |xártka-s| & ${ }^{*}$ GeMP/_P & Agr $[$ voi $]$ & ID-C[voi $] /[+$ son $]$ & $*[-$ long $] / T$ & ID-C[long] & ID-C[voi] \\
\hline a. $\quad$ ártkas & & & & $* * !$ & & \\
\hline b. Xártk:as & & & & $*$ & * & \\
\hline c. Xárt:ksas & $* !$ & & & & ** & \\
\hline d. $\quad$ árdk:as & & $* !$ & & & $*$ & $*$ \\
\hline e. Xárdgas & & & $* !$ & & & $* *$ \\
\hline
\end{tabular}

In (44), the underlying form contains a sequence of two short voiceless stops, which would violate *[-long]/T. Candidates $(\mathrm{d})$ and $(\mathrm{e})$, which repair this violation by voicing of the first stop or both stops, are ruled out by top-ranked AGR[voi] and ID-C[voi]/_[+son] respectively; note that these candidates would have otherwise been preferred to the winning candidate (b) and thereby demonstrate that AGR[voi] and ID-C[voi]/_[+son] must outrank *[-long]/T. Of the remaining candidates, (b) and (c) incur fewer violations of * [-long]/T than the faithful candidate (a), which is thus eliminated. Finally, the crucial ranking of *GEMP/_P over *[-long]/T is illustrated by the selection of candidate (b) over (c); the latter fully satisfies *[-long]/T by lengthening both voiceless stops, but in doing so creates a [t:k: sequence that violates * GEMP/_P and so is ruled out by this higher-ranked constraint. Candidate (b) therefore emerges as the winner.

The analysis developed above also handles stop-stop clusters in which the first stop is underlying voiced and the second voiceless, as illustrated in the tableau in (45).

(45) Pre-Hitt. */hegw-tu/ $\rightarrow$ *[hékwtuu] > Hitt. ekuddu 'let him/her drink' 3SG.IMP.ACT

\begin{tabular}{|c|c|c|c|c|c|c|}
\hline /heg ${ }^{\text {w-tu} /}$ & *GEMP/_P & Agr[voi] & ID-C[voi $] /[+$ +son $]$ & $*[-$ long $] / \mathrm{T}$ & ID-C[long] & ID-C[voi] \\
\hline a. hégwtu & & $* !$ & & & & \\
\hline b. hégw du & & & $* !$ & & & $*$ \\
\hline c. hék ${ }^{w}$ tu & & & & $* * !$ & & $*$ \\
\hline d. hék ${ }^{w}$ tru & & & & $*$ & $*$ & $*$ \\
\hline e. hék ${ }^{w}: t: u$ & $* !$ & & & & $* *$ & $*$ \\
\hline
\end{tabular}


The derivation in (45) is essentially the same as in (44). In this case, the faithful candidate (a) is ruled out by top-ranked AGR[voi], which is violated by its ${ }^{*}\left[g^{w} t\right]$ cluster. Once again, the form with progressive voice assimilation $\left({ }^{*}\left[g^{w} d\right]\right)$ - here, candidate (b) —is eliminated by ID-C[voi $] /[+$ +son $]$. The remaining three candidates (c-e) all violate the low-ranked general ID-C[voi] constraint, but otherwise have violation profiles identical to $(\mathrm{a}-\mathrm{c})$ in (44) above; candidate $(\mathrm{d})$ is then selected as the winner, being preferred to candidate (c) because it lengthens the cluster-final voiceless stop $\left({ }^{*}[-\mathrm{long}] / \mathrm{T} \gg\right.$ ID-C[long]) and to candidate (e) because it does not lengthen the cluster-initial voiceless stop $\left({ }^{*} \mathrm{GEMP} / \_\mathrm{P} \gg{ }^{*}[-\right.$ long $\left.] / \mathrm{T}\right)$.

4.3.3 Local summary: the phonology of Sturtevant's Law

The formal analysis developed in 4.3.1 and 4.3.2 thus predicts that underlying pre-Hittite voiceless obstruents were synchronically subject to gemination in exactly the contexts in which they develop into geminate stops in Hittite via STVL, and not in those contexts in which they develop into singletons (viz., before stops). The crucial ranking of phonological constraints necessary to generate this pattern is summarized in the Hasse diagram in (46):

(46) Pre-Hittite complete constraint ranking:

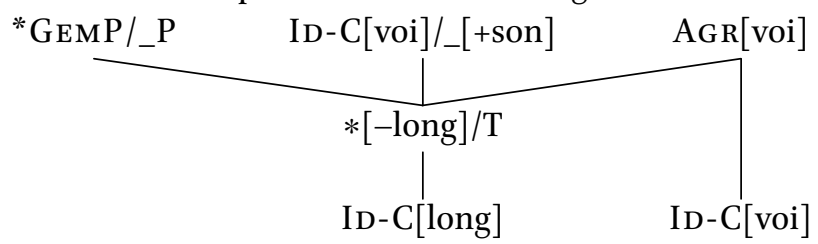

Under this analysis, just two constraints do the bulk of the work in STVL: (i) *[-long]/T, which drives gemination of voiceless obstruents; and (ii) * GEMP/ _P , which dominates * [-long]/T and thus blocks gemination of voiceless stops in pre-stop contexts.

The only innovation that distinguishes the stage of pre-Hittite modeled above from attested Hittite is the elimination of contrastive voicing specification ([ \pm voice $]$ in obstruents-in effect, the "dephonologization" of a now redundant acoustic cue to a contrast that has become marked by length ([ \pm long $])$. The nature of this change is discussed further in 5.2. 
If the analysis of STVL developed in the preceding sections is correct, it has some non-trivial implications for the reconstruction of the phonological system of PIE, as well as for diachronic phonological typology. These implications are evaluated in 5.1 and 5.2 respectively. In 5.3 , I briefly discuss the possibility of a synchronic analogue of STVL in the phonology of Hittite. I then conclude in 5.4 with a short discussion of some empirical and theoretical issues surrounding STVL that remain outstanding.

\subsection{The implications of Sturtevant's Law for Proto-Indo-European phonology}

Section 3.2 introduced a set of forms that were problematic under the traditional conception of STVL as an across-the-board sound change whereby pre-Hittite word-medial voiceless and voiced obstruents developed into Hittite (orthographic) geminate and non-geminate obstruents respectively. A subset of these forms - Hitt. nekuz (mehur) '(time of) evening', ekutta 'drank' and ekuddu 'let him/her drink' have been taken by Kloekhorst (2016) as the basis for some much broader claims about the reconstruction of the PIE phonological system. As discussed in more detail in 3.2.2 above, Kloekhorst argues that the non-geminate $\left[\mathrm{k}^{\mathrm{w}}\right]$ in these forms is the reflex of what is - under the traditional reconstruction of the PIE stop inventory - a PIE (breathy) voiced labiovelar stop in a surface cluster * $\left[-\mathrm{g}^{\mathrm{w} t}-\right]$ in which the first stop did not assimilate the voicing specification of the following stop. He thus rejects regressive obstruent voicing process (given in (11) above) as a PIE process, and on this basis, argues that PIE must have lacked contrastive voicing in obstruents; this leads him, in turn, to argue for the alternative PIE stop inventory in (25b) above, with a contrast between voiceless long, voiceless "preglottalized," and plain voiceless stops.

In section 4, however, I argued that these problematic forms can be explained straightforwardly if STVL is understood as a conditioned changespecifically, that voiceless stops underwent a conditioned split, undergoing gemination in most word-medial environments, but not in pre-stop contexts. As shown in 4.1, this analysis is empirically superior to that of Kloekhorst, since it accounts not only for the seemingly problematic forms noted above but also for the non-geminate $\left[\mathrm{k}^{\mathrm{w}}\right]$ in Hitt. šakuttai- 'thigh' and the (previously unnoticed) non-geminate [t] of Hittite forms like hartagga- 'bear' and watku- 'leap'; the former two items can be handled by an analysis like Kloekhorst's only by special stipulation and the last cannot be accounted for at all.

A second advantage of the analysis proposed here is its economy: it requires none of Kloekhorst's additional assumptions, allowing for both the Hittite and 
PNIE situations to be derived straightforwardly from the PIE phonological system as traditionally reconstructed, with a phonemic contrast between voiceless, voiced, and breathy voiced stops (i.e., (25a) above) and regressive obstruent voicing assimilation as part of the more general process of laryngeal feature assimilation in (47) (cf. Byrd 2018, 2070):61

(47) Regressive Laryngeal Feature Assimilation:

$[$-sonorant $] \rightarrow[\alpha$ voice, $\beta$ s.g. $] /$ — $[$-sonorant, $\alpha$ voice, $\beta$ s.g. $]$

"Obstruents (incl. */s/) assimilate to the laryngeal features of a following obstruent."

Under this view, PNIE continues the PIE phonological system unchanged. The only change between PIE and PA was the merger of breathy voiced and plain voiced stops (and, as a consequence, the simplification of the process in (47) to the form in (11) above). The resulting [ \pm voice] opposition was inherited into pre-Hittite, whence the synchronic Hittite system emerged by the regular, phonetically motivated sound change that is STVL.

It is not just economical, however, to avoid the Kloekhorst's (2016) assumptions about the PIE phonological system; these assumptions are also independently problematic. While a full assessment of his proposal is beyond the scope of this paper, a few remarks about the Anatolian evidence are in order here. One major issue with this proposal is that it offers no explanation whatsoever for the gemination of certain Hittite root-final underlying non-geminate obstruents before /s/-initial suffixes—regularly before the imperfective suffix/-sk:é-/ (e.g., akkuške- $\Leftarrow e k u / a k u$ - 'drink'; cf. (16c-e) above) and, more sporadically, before the 3SG.PST.ACT ending /-s/ (e.g., wakkiš 'bit'; cf. 3SG.NPST.ACT wāki).

This phenomenon is - as already noted in 2.2 above-elegantly explained as the result of prehistoric voicing assimilation: the historically voiced rootfinal stop was devoiced by the following * $s$ and then underwent STVL. When contrastive voice was lost in pre-Hittite, this pattern was reanalyzed as a morphophonemic gemination process that applied to roots that were historically subject to devoicing in the context of the affixes that triggered it. This view

61 As formulated in (47) the rule applies to all stops. Whether or not the rule in fact applied to [+spread glottis] segments in PIE depends on the status of BART HOLOMAE's LAW (BL; Bartholomae 1883, 48). I thus assume here that BL was a post-PIE innovation (cf. Collinge 1985, 7-10, Byrd 2015, 22; pace Mayrhofer 1986, 110); however, none of the further claims advanced in this paper depend on this assumption, since BL would no longer have been relevant after the PA loss of the distinction between breathy voiced and plain voiced stops (Melchert 1994, 6o). 
is consistent with the fact that the gemination process sustains exceptions: it occurs in the imperfective eku/aku- 'drink', but not in the imperfectives of all roots with a synchronic root-final non-geminate (< voiced) obstruent, such as Hitt. wek- 'demand' (IPFV wekiške-). ${ }^{62}$

Another serious problem for Kloekhorst's (2016) reconstruction relates to the mechanism that he invokes to motivate the hypothesized change between the PIE and PNIE stop systems - in particular, the putative degemination of the voiceless geminate series, which Kloekhorst attributes to an innovative dispreference for geminate consonants in PNIE. Such a dispreference is wellestablished at the PNIE level, as the NIE languages exhibit a diverse set of strategies for repairing geminates at morpheme boundaries (for an overview see Byrd 2015, 43-48 with references), and several of these are even reconstructible for PNIE, including degemination of */s-s/ and (probably) $* / \mathrm{m}$ $\mathrm{m} /$, as well as the well-known "Double Dental rule" whereby the first stop in a coronal stop-stop sequence underwent affrication (*[ts-t], *[dz-d]). ${ }^{63}$ Yet Kloekhorst's claim that this dispreference is a PNIE innovation is contradicted by evidence for all three processes in Anatolian: $64 * / \mathrm{s}$-s/-degemination is attested in 2SG.N PST.ACT mūši 'you shall satiate yourself' $(\leftarrow /$ mus-si/ per Yakubovich 2006b, 115; cf. Yates 2018 with further argumentation); */m-m/-degemination is likely reflected in Hitt. ištamina- 'ear' (Melchert 2007/8, 185); and the "Double Dental rule" is uncontroversially continued in Hittite and Luwian (Melchert 1994), e.g., 2PL.NPST.ACT Hitt. azzašteni ([ałs-trérni]) 'you eat' ( $\Leftarrow$ ed/ad- 'eat'), 2PL.IMP.ACT CLuw. azzaštan 'eat!' ( $\Leftarrow a d$ - 'eat'). ${ }^{65}$ The existence

62 The non-application of gemination in such forms awaits a satisfactory explanation. In the case of wek-, it is perhaps related to the verb's historical origin as a PIE "Narten formation" *wék- (per Melchert 2014, 255-256), but the details of this development remain to be worked out.

63 For degemination of */s-s/ and the "Double Dental rule" as synchronic PIE processes, see Mayrhofer (1986, 110-112, 120-121), and Byrd (2018, 2071) for degemination of */m-m/. I follow Melchert $(2003,154-155)$ in analyzing the "Double Dental rule" as an affrication process (rather than ${ }^{*} s$-epenthesis).

64 It is also contradicted by the development of the few morpheme-internal geminates that are reconstructible for PIE, which do not undergo degemination in PNIE-e.g., PIE *atta'daddy' > Hitt. atta-, Gk. > $\alpha \tau \tau \alpha$, Lat. atta, Goth. atta (see further Byrd 2015, 45-46 and Sandell 2015, 144-146 with references). Kloekhorst's (2016) objections to the reconstruction of the relevant lexical items do not withstand scrutiny-in particular, with respect to the remarkable correspondence set for 'daddy'.

65 It is pointed out by Jäntti $(2017,42-44)$ that cross-linguistically phonemic geminates and the active avoidance of (some) heteromorphemic geminates are not strictly mutually exclusive; he therefore suggests that the "Double Dental rule" may not be motivated by a dispreference for geminates at all. However, it is clear from the independent existence 
of these processes in Anatolian guarantees their reconstruction for PIE, and in turn, of their phonological motivation, a dispreference for geminates at the PIE stage. Accordingly, this dispreference cannot be an innovation of PNIE; Kloekhorst's account is thus deprived of any motivation for the degemination of voiceless stops that allegedly occurred between PIE and PNIE.

The broad take-away from the discussion above is that Hittite provides no empirical support for the radical revisions to the PIE phonological system argued for by Kloekhorst (2016); on the contrary, it supports the traditional reconstruction of this system, from which the Hittite system can be derived primarily by the application of STVL as defined in 4.1 above. The only remaining obstacle to this proposal, then, is a typological objection raised by Kloekhorst (2016) and Jäntti (2017); this point is taken up in 5.2 below.

\subsection{The implications of Sturtevant's Law for diachronic phonological typology}

One of Kloekhorst's (2016) major arguments for the revised reconstruction of the PIE phonological system proposed by Kortlandt (2010) is a critique of Melchert's (1994, 14-21) view of STVL as a pre-Hittite sound change whereby voiceless obstruents underwent gemination and then contrastive voicing in obstruents was lost. Kloekhorst disputes this change on typological grounds, stating that "spontaneous, unconditioned lengthening/gemination of original short stops is a development that, as far as I know, is cross-linguistically unattested" (2016, 235-236; cf. Jäntti 2017, 45).

As a critique of the account of STVL proposed in the preceding sections, there are a few serious problems. The first is the claim that there are no typological parallels for the reanalysis of an obstruent voicing contrast as a length contrast, which would involve "lengthening/gemination of original short stops." In fact, several potential cases of this development are adduced by Blevins's (2004, 175-177), who proposes that this type of reanalysis is a viable pathway to the emergence of new geminates. Of these cases, Kloekhorst $(2016,236)$ and Jäntti (2017) argue explicitly against just one (Proto-Dravidian > Old Tamil), thus appearing to dismiss out of hand the phenomena in Meidob Nubian and in Didinga (both Nilo-Saharan) cited by Blevins that are plausibly explained if just

of the two cited degemination processes that there is a "conspiracy" (Kisseberth 1970) to avoid heteromorphemic geminates; any analysis that separates these phenomena thus misses this important generalization. Furthermore, Jäntti fails to consider whether the phenomena he cites may in fact reflect an emergent dispreference for geminates, thus affecting heteromorphemic geminates but not underlying geminates, as was the case in PIE itself (cf. n. 64 above). 
such a diachronic development took place in certain contexts. ${ }^{66}$ Yet without any explicit refutation of these examples, the strong typological claim-viz., that such a diachronic reanalysis is unattested — can hardly constitute grounds on which to categorically reject it for pre-Hittite. ${ }^{67}$

The other typological objection raised by Kloekhorst $(2016,235)$ is to "spontaneous, unconditioned lengthening/gemination" (similarly Jäntti 2017, 45). Whether or not this objection is generally valid, it simply does not apply to the account of STVL advanced above. Under this view, STVL was precisely a conditioned sound change: word-medial voiceless obstruents were subject to gemination in contexts where the durational contrast between voiceless and voiced obstruents was robustly cued and not elsewhere.

Furthermore, it is not the case that gemination was "spontaneous;" rather, as argued already at length by Melchert (1994, 18-21), the structural conditions of pre-Hittite were favorable to a reanalysis of the voicing contrast. First, it is likely that already in PA — and arguably even in PIE — the contrast between voiced and voiceless obstruents was neutralized in word-final position, ${ }^{68}$ which is consistent with the lack of an orthographic gemination contrast in this position in Hittite. ${ }^{69}$ Second, between PA and pre-Hittite the contrast between voiced and

66 The case of Didinga is particularly compelling: a synchronically aberrant pattern whereby all syllable-final stops undergo gemination can be explained quite naturally as the reanalysis of a cross-linguistically common syllable-final stop devoicing process (cf. Blevins 2004, $176)$.

67 In my view, Blevins' (2004, 176) observation that it is difficult "to find well-documented cases" of this change is most likely due to the relatively small number of languages which (i) have the right structural conditions for the reanalysis and (ii) - the more seriously limiting factor - whose diachrony is well-documented and well-understood.

68 Melchert $(1994,85)$ has argued for word-final voicing of voiceless obstruents in PA, which he takes to be a PIE phenomenon as well on the basis of Italic evidence (cf. Weiss 2011, $155 \mathrm{n} .34 ; 2014,139)$. As is well-known, such a pattern is typologically rare at best (potentially Lezgian; Yu 2004), and it has even been argued by Kiparsky $(2006 ; 2008,48)$ that it cannot emerge in natural language. I take no strong stance on Melchert's broader prehistoric claims, but his observation concerning the synchronic situation in Hittite is surely correct - viz., that there is no positive evidence for a length contrast in word-final obstruents (cf. n. 69 below).

69 In particular, direct evidence for word-final geminate stops is lacking, even in environments where the writing system perhaps allows for it (such as when the word is followed by a vowel-initial clitic), although it remains difficult to wholly exclude a purely orthographic explanation. Kloekhorst $\left(2014,5^{62-563} ; 2016,221-222\right)$ has claimed that there is indirect evidence for a word-final geminate stop in Hitt. šep $(p) i t(t)$ - '(type of) grain', which in his view continues a nominal paradigm with fixed root stress: NOM/ACC.SG PIE * sép-

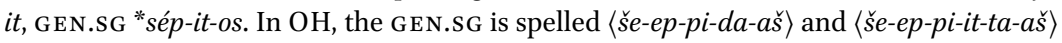
with both singleton and geminate reflexes of intervocalic ${ }^{*} t$. Kloekhorst contends that the singleton spelling is due to PA lenition, whereas the geminate has been analogically 
voiceless obstruents was also neutralized word-initially, ${ }^{70}$ in all likelihood in favor of the voiceless set in view of certain orthographic facts and phonological evidence from reduplication (the latter of which points to phonemic merger; see Melchert 1994, 18-20). ${ }^{71}$ Finally, PA or pre-Hittite innovated a process such that word-medial voiceless obstruents - except voiceless stops before stopswere subject to allophonic gemination, as outlined in 4.3 above.

An important consequence of the first two developments was that by preHittite [voice] was contrastive only in word-medial pre-sonorant obstruents: [voice] was neutralized at word boundaries, and in pre-obstruent position was a predictable function of the following segment. Due to the third development, moreover, all such medial obstruents would have contrasted on the surface not only for [ \pm voice] but also for [ \pm long] — schematically, [T:] vs. [D]. This situation, in which the underlying contrast was redundantly marked, would have been amenable to a reanalysis whereby [long] replaced [voice] as the phonemic representation of this contrast and [voice] was dephonologized. The resulting system corresponds precisely to attested Hittite: [long] is phonologically active and [voice] inactive (as discussed in 2.2 above).

Yet what is perhaps more difficult to explain than how such a reanalysis took place in the context of a system with allophonic gemination of voiceless obstruents is how this process arose in the first place. Like other phonological processes, gemination must have begun with gradient changes in phonetic

generalized from the NOM/ACC.SG, where the word-final stop was not subject to lenition (cf. 2.1 above). The PIE status of such forms is doubtful, however; a non-IE origin for šep $(p) i t(t)$ - was previously suggested by Kloekhorst $(2008,744-745)$ and more recently Hyllested (to appear) has argued specifically for borrowing from Akkadian. Yet even supposing the word were inherited, there are at least two easier explanations available for its spelling. First, the geminate may be due to interparadigmatic analogy with other ${ }^{*} t$ stems, which in Hittite are attested only with geminate reflexes of the stop in their nominal paradigms. Alternatively, the paradigm originally had mobile stress-i.e., NOM/ACC.sG PIE *ép-it, GEN.SG * s(e)p-it-ós (and renewed N.NOM/ACC.PL * sép-it-eh $h_{2}$ )—in which case the intervocalic geminate of the GEN.SG is regular and the singleton due to analogy with the NOM/ACC.PL. This hypothesis would have the added benefit of offering a potential explanation for occasional spellings like $\langle$ še-pi-it $\rangle$ (e.g., KBo 4.2 i 9) with a singleton reflex of ${ }^{*} p$, which would have been subject to lenition in the noun's oblique case forms (and from there analogically generalized to the NOM/ACC.SG).

70 I follow Melchert (2019) in rejecting "the implausible claim" of Kloekhorst (2010, 2016) that Hittite has a "partially preserved" obstruent voicing contrast in word-initial position.

71 As pointed out by Melchert $(1994,18)$, initial devoicing was likely a post-PA areal development (cf. Watkins 2001), occurring also in Luwian and, more clearly, in Lycian and Lydian, whose alphabetic scripts allow the change to be observed more directly. On the distribution of geminate obstruents in reduplication see further Yates and Zukoff $(2018,209)$. 
implementation (e.g., Bermúdez-Otero 2015) - more specifically, in increased closure duration in voiceless stops. Such an increase would have the effect of reinforcing the existing durational contrast between longer voiceless and shorter voiced obstruents (cf. 4.2.1 above); it can therefore be understood as a type of CUE ENHANCEMENT (Keyser and Stevens 2001, 2006), and viewed in this light, potentially offer some insight into the development of the pre-Hittite phonological system.

It was observed by Repp $(1982,87)$ that acoustic cues often stand in a trading relationship, such that "a change in the setting of one cue (which, by itself, would have led a change in the phonetic percept) can be offset by an opposed change in the setting of another cue so as to maintain the original phonetic percept." Subsequent work (see especially Kirby 2010) has called attention to the importance of such CUE TRADING in phonological change-in particular, as the mechanism underlying transphonologization (cf. 4.2.1 above). This type of change originates in gradient probabilistic enhancement of some nonprimary acoustic cue to a phonological contrast, which may itself be a response to decreases in the original primary cue to this contrast. Listeners are consequently exposed to an increasing number of tokens in which the contrast is reliably cued by this previously redundant cue and the original cue may be uninformative. In Kirby's (2010) model, the growing reliability of the innovative cue makes it even more likely to be enhanced, as speakers adapt their production in an effort to accommodate the communicative needs of their listeners. Over generations, these gradient phonetic changes may therefore have a cumulative effect: the cue targeted for enhancement becomes the primary cue of the contrast and gets phonologized; the original cue becomes largely redundant and may be dephonologized. ${ }^{72}$

While it is impossible to be certain about exactly what factors led preHittite speakers to start lengthening voiceless obstruents, there is some independent evidence to support the hypothesis that it was an adaptive response to other changes in the phonetic realization of contrastive obstruent voicing. ${ }^{73}$

72 Kirby (2010) tests several computation models of transphonologization on a change in Seoul Korean whereby the contrast between "lenis" and aspirated stops, originally cued primarily by VOT, came to be cued instead by pitch (Fo) on the following vowel. The model that accounts best for this change incorporates both probabilistic enhancement of Fo and a bias factor driving reduction of VOT differences, outperforming other models that include only enhancement or reduction.

73 In particular, it is difficult to say anything with certainty about what Kirby $(2010,3)$ refers to as the "cue selection" problem-in this case, why the durational contrast between voiced and voiceless obstruents was targeted for enhancement rather than some other cue (e.g., VOT). I leave this question open for future research. 
Specifically, the complete neutralization in pre-Hittite of the inherited contrast between voiceless and voiced obstruents (discussed just above) in word-initial position suggests that some acoustic cue or cues that were crucial to licensing obstruent [voice] contrasts at an earlier stage had become unreliable. ${ }^{74}$ As the [voice] contrast was threatened by these changes (whatever their exact nature), pre-Hittite speakers would have been pressured to enhance it along some other phonetic dimension. Some speakers may then have begun to produce voiceless obstruents with greater closure duration, thus reinforcing the existing durational contrast between them and the voiced set; this tendency was eventually phonologized as allophonic gemination, thereby setting the stage for its phonemicization and the concomitant dephonologization of redundant [voice].$^{75}$

Significantly, the neutralization of the inherited [voice] contrast in wordinitial position also falls out naturally from a diachronic scenario in which closure duration is (increasingly) the only reliable cue to obstruent voicing, since it is precisely in word-initial position that durational contrasts are difficult to maintain, being both relatively hard to produce and hard to perceive..$^{76,77}$

74 There is also comparative support for such contrast-destabilizing phonetic changes at the PA level or as a post-PA prehistoric areal phenomenon. Taken together, the Anatolian languages present what might be called an "obstruent voicing conspiracy:" synchronically, no Anatolian language has obstruents that contrast minimally for [voice], despite the fact that such contrasts were inherited into each. Thus, for instance, in Lycian the contrast between intervocalic voiceless and voiced stops has become a contrast between stops and fricatives (cf. Melchert 1994, 21, 300-307).

75 Note that the dephonologization of [voice] between pre-Hittite and Hittite need not have involved complete phonetic devoicing of all voiced obstruents; rather, the bundle of acoustic cues associated with the erstwhile [voice] contrast - including closure voicingmay have been reinterpreted as secondary acoustic cues of the new length contrast (just as in the Seoul Korean example discussed by Kirby 2010, 82-86). In particular, there is no good reason to assume phonetic devoicing of pre-sonorant inherited voiced stops; on the contrary, the assumption that these remained voiced phonetically in pre-Hittite and the other second millennium BCE Anatolian languages that show STVL-like phenomena makes it easier to explain how they generally developed into voiced fricatives in Lycian in the first millennium (cf. Melchert 1994, 21) and, still more proximately, "rhotacism" of *d in Hieroglyphic Luwian (on which see Morpurgo-Davies 1982).

76 The cross-linguistic rarity of word-initial geminate consonants is generally ascribed to such factors (cf. Muller 20o1; Pająk 2013). The weaker durational contrast between wordinitial geminates and singletons is also supported by detailed phonetic studies of Swiss German (Kraehenman and Lahiri 2008) and of Cypriot Greek (Armosti 2009).

77 If it is true that perceptual constraints prevented consonant duration from being used to enhance the word-initial voicing contrast in pre-Hittite and thus to prevent the merger of the [+voice] and [-voice] obstruents, it might be expected on the same grounds that all word-initial obstruents would develop into non-geminates in Hittite. Such a development is in my view likely (and in a similar vein, Kloekhorst 2016, 218 suggests that PIE voiceless 
This hypothesis thus offers a unified explanation for word-initial devoicing of voiced obstruents and word-medial gemination of voiceless obstruents, both of which are ultimately driven by pre-Hittite changes in the phonetic realization of these obstruents that made them difficult for listeners to reliably distinguish from one another.

I conclude, then, that STVL is not an impossible sound change nor even an especially unlikely one, as the objections of Kloekhorst (2016) and Jäntti (2017) imply. Rather, STVL constitutes a fairly clear case of transphonologization, atypical (arguably) only in its end result-i.e., that consonant duration emerges as the primary cue of a historical $[ \pm$ voice $]$ contrast; this trajectory may be typologically uncommon, but it has a plausible phonetic basis (viz., the greater duration of voiceless obstruents than voiced) and was facilitated by structural conditions in pre-Hittite. I therefore take Hittite (with Kümmel 2007, 176) as support for Blevins' (2004, 175-177) proposal that geminates may arise diachronically from the reinterpretation of a historical obstruent voicing contrast, and as encouragement that further research will uncover more examples of this development elsewhere.

\subsection{A synchronic analogue of Sturtevant's Law?}

If the analysis of STVL proposed above is correct, then the regular Hittite outcomes of all inherited voiceless stops in pre-stop contexts were non-geminate stops. As hinted at in 4.1, however, there is some uncertainty about whether the expected historical distribution was maintained in attested Hittite or whether it had been disrupted by analogy. A question that bears directly on this issue is what happened in Hittite when an underlying sequence of geminate stop plus stop was produced synchronically by morpheme concatenation: Was the underlying geminate realized as a singleton, as in the historically expected form? Or did it surface as a geminate, "analogically restored" on the basis of other paradigmatic forms?

The relevant configuration is not at all rare in Hittite, arising, in particular, in verbal inflectional paradigms. Hittite has a non-trivial number of verbs with underlying stem-final geminate stops and also inflectional endings that begin with a stop (or the affricate [ $\mathfrak{t s}$ ], which comes from a stop historically). (48) provides a list of these endings and a sample of verbal stems that when com-

stops - in his view, underlyingly [+long] — were realized as [-long] word-initially). However, as noted already in section 3 the normal means of encoding a $[ \pm$ long] contrast (viz., geminate vs. non-geminate spelling) would not have been available word-initially, and I am aware of no phonological evidence that supports one interpretation or the other; the [ \pm long] status of Hittite word-initial obstruents therefore remains uncertain. 
bined give rise to this configuration; all of the verbs included have a post-vocalic stem-final geminate stop and have multiple attestations with one or more of the relevant endings: ${ }^{78}$

\begin{tabular}{|c|c|c|c|}
\hline$-t t i$ & (2SG.NPST.ACT) & $a k(k)-$ & 'die’ \\
\hline$-z i$ & (3SG.NPST.ACT) & epp/app- & 'take' \\
\hline$-t /-t t a$ & (2/3SG.PST.ACT) & haššikk- & 'become satiated' \\
\hline$-t t a(r i)$ & (2/3SG.NPST.MID) & huwapp/hupp- & 'throw' \\
\hline$-\operatorname{ttat}(t(i))$ & (2/3SG.PST.MID) & ištap $(p)-$ & 'stop up' \\
\hline -tteni & (2PL.NPST.ACT) & lapp- & 'light up' \\
\hline -tten & (2PL.PST.ACT) & šak $(k)-$ & 'know' \\
\hline -tten & (2PL.IMP.ACT) & šupp- & 'sleep’ \\
\hline -ttuma $(r i)$ & (2PL.NPST.MID) & dakk- & 'resemble' \\
\hline -ttumat $(i)$ & (2PL.PST.MID) & tarupp- & 'gather' \\
\hline \multirow[t]{2}{*}{-ttumat(i) } & (2PL.IMP.MID) & teripp- & 'plow' \\
\hline & & upp- & 'rise' \\
\hline
\end{tabular}

It was established in 4.1 that post-vocalic geminate stops can be expressed orthographically in pre-consonantal position, e.g., $\left\langle s ̌ a-a k-k a_{4}-a h-h i\right\rangle$ 'I know' to šak $(k)$-in (48) and the other examples cited in (30) above, although "simplified" singleton spellings in this context are common (e.g., $\left.\left\langle\check{s} a-k a_{4}-a h-h i\right\rangle\right)$. Productive affixation of inflectional endings to the verbal stems in (48) yield hundreds of attested forms in which a pre-stop underlying geminate stop could be spelled geminate. It is therefore a striking fact that if the forms in (31) above are correctly analyzed as containing the ending - $\operatorname{atta}(t)$ (as argued in 4.1) - then prestop geminate stops are (to my knowledge) systematically unattested in Hittite. Thus, for instance, the 2PL.NPST.ACT of epp/app-could be spelled $\mathrm{x}\langle a p-p a(-a t)-$ $t e-n i\rangle$ - a case in which, moreover, the geminate spelling of the stem-final geminate stop would facilitate the spelling of the ending-initial geminate-but this form is never found, nor do comparable forms occur for the other verbal stems in (48).

78 I assume that $a k(k)-$, šak(k)-, and ištap $(p)$ - in (48) and other hi-verbs of this type have underlying stem-final geminate consonants that undergo a morphologically conditioned lenition process in certain strong stem forms (whence, e.g., 3SG.NPST.ACT aki 'dies'). This analysis is supported by the consistent geminate stop in derived forms (e.g., aggātar 'death'). For the origin of degemination in these verbs see Melchert (2012). 
In my view, it is unlikely that the categorical absence in Hittite of orthographic geminates before stops is due purely to orthographic factors. Accordingly, I propose that Hittite has preserved the surface distribution of geminate stops that resulted from STVL by innovating a degemination process that applies to underlying geminate stops in pre-stop contexts, including those created synchronically by adding inflectional endings to the verbal stems in (48). This degemination process is represented in rule-based form in (49):

(49) Hittite pre-stop stop degemination:

[-sonorant, - continuant $] \rightarrow[-$ long $] /$ _ $[$-sonorant, - continuant $]$

The emergence of the rule in (49) would constitute a classic case of "rule inversion" (Vennemann 1972): at an earlier historical stage, voiceless stops were subject to gemination before non-stops, which ultimately caused them to be reanalyzed as phonemic geminates; (49) "undoes" this change in the complementary set of environments (i.e., before stops), mapping the innovative [+long] stops to [-long] stops where the conditions for the earlier rule's application were not met. ${ }^{79}$ From the optimality-theoretic perspective adopted in 4.3, (49) functions as a repair for the exact same markedness constraint that contextually blocked gemination in pre-Hittite, i.e., GEMP/_P in (42) above. Under this view, the phonological grammar has in this respect remained stable diachronically while the properties of its inputs-i.e., morphemes containing obstruentshave been restructured.

\subsection{Conclusions and outstanding issues}

In this paper, I have defended the traditional view of STVL as a sound change that occurred in the prehistory of Hittite whereby inherited word-medial voiceless and voiced stops developed into geminate and non-geminate stops and contrastive obstruent voicing was lost. However, I have also proposed a new, phonetically motivated constraint on the operation of this change, which accounts for Hittite forms that were problematic or unexplained under previous analyses (Melchert 1994, 61; Kloekhorst 2016): voiceless stops did not undergo gemination in pre-stop contexts and thus became Hittite nongeminate stops. The Hittite stop system is thus better derived directly from

79 Note, however, that morpheme-internal pre-stop voiceless stops—such as the */t/ in the inherited word for 'bear' (see 4.1 above) — would never have been been subject to gemination and thus would never have been reanalyzed as geminates in Hittite; synchronically, then, such consistently pre-stop stops would be underlyingly [-long] rather than derived by (49). 
the PIE system as traditionally reconstructed by a historical reanalysis of contrastive voice as contrastive length in those environments in which this contrast was robustly cued-i.e., by STVL.

The account of STVL advanced here still leaves a number of important issues outstanding. One that pertains directly to Hittite concerns the historical development of word-initial and especially word-final obstruents. I have generally left aside this issue because of uncertainties in the synchronic phonological properties of Hittite obstruents in these positions, where orthographic limitations problematize their interpretation; further research may shed additional light on the status of these obstruents and thus allow for a clearer assessment of their diachronic development and their implications for the reconstruction of PA and PIE phonology.

Another question relates more broadly to the STVL-like phenomena observed in the other Anatolian languages attested in cuneiform script in the 2nd millennium BCE, Luwian and Palaic. It is generally thought that something like STVL occurred in the prehistory of these languages (Melchert 1994, 21, 19o, 251-252) - in particular, since each attests examples of historical voiceless stops that are spelled geminate, e.g., (50): 80

(50) a. PIE *-te- > PA *-ten > (e.g.) Pal. $\langle s ̌ i(-\imath)-i t-t a-a n\rangle$ 'prod!'

$$
\text { 2PL.IMP.ACT }
$$

b. PIE/PA *-tu > (e.g.) CLuw. $\langle a-r i-y a-a d-d u\rangle$ 'let him raise' 3SG.IMP.ACT

(cf. Hitt. -ttu)

Melchert $(1994,21)$ has suggested that these languages inherited a situation similar to what was posited for pre-Hittite in 4.3 above, with the inherited obstruent [voice] contrast preserved and allophonic gemination of wordmedial voiceless obstruents. While this system may have developed independently in these languages in the same way as it did in Hittite (i.e., with the subsequent loss of contrastive voice), the Palaic and Cuneiform Luwian evidence for the historical development of voiceless and voiced stops has never been comprehensively gathered and assessed. It remains possible, then, that such systematic examination of the data will yield differences-minor or majorfrom what is observed in Hittite and thus lead to an alternative picture of the diachronic development of their phonological systems. Whatever the result, such an examination is an important task for future research.

80 For a recent skeptical perspective on the Luwian situation, however, see Simon (2017). 
Finally, there is a methodological lesson that emerges from this study of STVL. This point concerns what has been commonly referred to since Sturtevant (1929) as the "Indo-Hittite question"-in essence, what is the nature of the relationship between Anatolian and the other IE languages? At this point there can be no question that Hittite and the other Anatolian languages are conservative in certain respects, preserving PIE features vis-à-vis PNIE and its daughters (e.g., consonantal reflexes of the laryngeals, two grammatical genders), and there is now general agreement that Anatolian was the first to "hive off" (Watkins 1998, 31) from the rest of the family and so did not share in some set of common innovations that can be reconstructed for their common ancestor (see Oettinger 2013-2014, 2017; Jasanoff 2017; Melchert 2018, to appear c, i.a.).

The early attestation of the Anatolian languages, their established archaism, and their unique position in the IE family tree all conspire to make it exceptionally tempting to take what appear to be exceptional word forms or linguistic features found in these languages as evidence that PIE differed, perhaps in quite radical ways, from how it has been traditionally reconstructed on the basis primarily of NIE evidence. This study urges caution in this respect:81 it was demonstrated in 4.1 that the Hittite forms in (24), which were interpreted by Kloekhorst (2016) as evidence for an Anatolian phonological archaism (viz., no regressive assimilation) and used as support for a fundamentally different alternative reconstruction of the PIE stop system (cf. 3.2.2 above), are neither archaic nor even irregular; rather, when subjected to typologically and theoretically informed phonological analysis, these data reveal a deeper regularity in the operation of STVL-namely, that the historical outcome of pre-stop voiceless stops are Hittite [-long] stops.

\section{Acknowledgments}

I am deeply grateful to the members of the Indo-European \& Modern Linguistic Theory research group (especially Ryan Sandell and Sam Zukoff), as well as to Michael Weiss and Craig Melchert; this paper benefited significantly from their critical feedback. I would also like to thank Miyu Akao, John Clayton, Anahita Hoose, and Teigo Onishi for their discussion and comments on early drafts; two

81 Caution is perhaps especially in order for Anatolianists, since it is a general principle that one should be wary of reconstructions that instantiate "Teeter's Law" ("[T] he language of the family you know best always turns out to be the most archaic;" Watkins 1976, 247). 
anonymous reviewers at IEL; and the audience of the 37th Annual East Coast Indo-European Conference, where a preliminary version of this work was presented.

\section{References}

Adiego, Ignacio-Javier. 2001. "Lenición y acento en protoanatolio." In Anatolisch und Indogermanisch: Akten des Kolloquiums der indogermanischen Gesellschaft, Pavia, 22-25 September 1998, edited by Onofrio Carruba and Wolfgang Meid, 11-18. Innsbruck: Institut für Sprachwissenschaft der Universität Innsbruck.

Armosti, Spyros. 20o9. "The Phonetics of Plosive and Affricate Geminates in Cypriot Greek." PhD thesis, University of Cambridge.

Bartholomae, Christian. 1883. Handbuch der altiranischen Dialekte. Leipzig: Breitkopf \& Härtel.

Beckman, Jill N. 1998. "Positional Faithfulness." PhD thesis, University of Massachusetts, Amherst.

Beekes, Robert S.P., and Michiel A.C. de Vaan. 2011. Comparative Indo-European Linguistics: An Introduction. 2nd ed. Amsterdam / Philadelphia: John Benjamins.

Bermúdez-Otero, Ricardo. 2015. "Amphichronic explanation and the life cycle of a phonological process." In The Oxford Handbook of Historical Phonology, edited by Patrick Honeybone and Joseph C. Salmons, 374-399. Oxford / New York: Oxford University Press.

Blevins, Juliette. 2004. Evolutionary Phonology: The Emergence of Sound Patterns. Cambridge, UK / New York: Cambridge University Press.

Blevins, Juliette. 2018. "Evolutionary Phonology and the life cycle of voiceless sonorants." In Typological Hierarchies in Synchrony and Diachrony, edited by Sonia Cristofaro and Fernando Zúñiga, 29-58. Amsterdam / Philadelphia: John Benjamins.

Borg, Alexander. 1997. "Maltese phonology." In Phonologies of Asia and Africa, edited by Alan S. Kaye, 1:245-285. Winona Lake, IN: Eisenbrauns.

Byrd, Andrew M. 2012. "The use of linguistic typology \& universals in Indo-European linguistics, with a brief note on the Hittite $s \sim$ Luwian $t$ correspondence, Lexington, KY, 13-15 April 2012." Paper presented at the 79th Annual Southeastern Conference on Linguistics (Slides available at: https://www.academia.edu/1524677/The_Hittite _s_Luvian_t_Correspondence)

Byrd, Andrew M. 2015. The Indo-European Syllable. Leiden / Boston: Brill.

Byrd, Andrew M. 2018. “The phonology of Proto-Indo-European.” In Handbook of Comparative and Historical Indo-European Linguistics, edited by Jared S. Klein, Brian D. Joseph, and Matthias Fritz, 2056-2079. Berlin / New York: de Gruyter.

Byrd, Dani. 1993. “54,00o American stops.” UCLA Working Papers in Phonetics 83: 97-116. 
Chodroff, Eleanor, and Colin Wilson. 2014. "Burst spectrum as a cue for the stop voicing contrast in American English." Journal of the Acoustical Society of America 136: 2762-2772.

Clements, George N., and Sylvester Osu. 2002. "Explosives, implosives, and non-explosives." In Laboratory Phonology 7, edited by Carlos Gussenhoven and Natasha Warner, 299-35o. Berlin / New York: de Gruyter.

Cohen, Paul S., and Adam Hyllested. 2018. "The Anatolian dissimilation rule revisited." Papers in Historical Phonology 3: 96-122.

Cole, Ronald A., and William E. Cooper. 1975. "Perception of voicing in English affricates and fricatives." Journal of the Acoustical Society of America 58: 1280-1287.

Collinge, N.E. 1985. The Laws of Indo-European. Amsterdam / Philadelphia: John Benjamins.

Čop, Bojan. 1955. “Notes d' étymologie et de grammaire hittite." Revue hittite et asianique 13: $63-71$.

Čop, Bojan. 1963. "Zur hethitischen Schreibung und Lautung." Linguistica 5: 21-46.

Davis, Stuart. 2011. "Geminates." In The Blackwell Companion to Phonology, edited by Marc van Oostendorp, Colin J. Ewen, Elizabeth Hume, and Keren Rice, 837-859. Oxford / Malden, MA: Blackwell.

Denes, Peter. 1955. "Effect of duration on the perception of voicing." Journal of the Acoustical Society of America 27: 761-764.

Dmitrieva, Olga. 2011. "Asymmetries between production and perception of consonant length." Studies in the Linguistic Sciences: Illinois Working Papers 36: 1-15.

Dmitrieva, Olga. 2012. "Geminate Typology and the Perception of Consonant Duration." $\mathrm{PhD}$ thesis, Stanford University.

Dmitrieva, Olga. 2015. "The role of context sonority in the typology and perceptibility of geminate consonants." Paper presented at the 2015 International Congress of the Phonetic Sciences Satellite Workshop on Geminate Consonants Across the World, Glasgow, 12 August 2015 (Slides available at: http://web.ics.purdue.edu/ odmitrie/ slides/Dmitrieva_ContextSonority_GemCon_ICPhS2015.pdf).

Dmitrieva, Olga. 2017. "Production of geminate consonants in Russian: implications for typology." In The Phonetics and Phonology of Geminate Consonants, edited by Haruo Kubozono, 34-65. Oxford / New York: Oxford University Press.

Dmitrieva, Olga. 2018. "The role of perception in the typology of geminate consonants: effects of manner of articulation, segmental environment, position, and stress." Language and Speech 61 (1): 43-70.

Ehrenhofer, Lara. 2013. "Processing of Medial Geminate and Singleton Consonants in Swiss German: Behavioural and ERP Evidence." Master's thesis, Oxford University.

Eichner, Heiner. 1973. "Die Etymologie von heth. meur." Münchener Studien zur Sprachwissenschaft 31: 53-107.

Eichner, Heiner. 1975. "Die Vorgeschichte des hethitischen Verbalsystems." In Flex- 
ion und Wortbildung: Akten der V. Fachtagung der Indogermanischen Gesellschaft, Regensburg, 9. bis. 14. September 1975, edited by Helmut Rix, 71-103. Wiesbaden: Reichert.

Eichner, Heiner. 2015. "Das Anatolische in seinem Verhältnis zu den anderen Gliedern der indoeuropäischen Sprachfamilie aus aktueller Sicht." In Diachronie und Sprachvergleich. Beiträge aus der Arbeitsgruppe "Historisch-vergleichende Sprachwissenschaft" bei der 40. Österreichischen Linguistiktagung 2013, edited by Thomas Krisch and Stefan Niederreiter, 11-24. Innsbruck: Institut für Sprachen und Kulturen der Universität Innsbruck.

Eichner, Heiner. 2018. "Consonants and vowels: some problems of the historical phonology of the Luwic languages." Paper presented at "'Luwic' Dialects: Inheritance and Diffusion." $5^{\text {th }}$ Workshop of the 'Luwic' Dialects Project, Santiago de Compostela, 25-26 January 2018.

Einarsson, Stefán. 1932. "Parallels to the stops in Hittite." Language 8 (3): 177-182.

Flemming, Edward. 1995/2002. Auditory Representations in Phonology. New York: Routledge.

Flemming, Edward. 2004. "Contrast and perceptual distinctiveness." In PhoneticallyBased Phonology, edited by Bruce Hayes, Robert Kirchner, and Donca Steriade. Cambridge: Cambridge University Press.

Flemming, Edward. 2005. "Speech perception and phonological contrast." In The Handbook of Speech Perception, edited by David B. Pisoni and Robert E. Remez, 156-181. Malden, MA / Oxford: Blackwell.

Goedegebuure, Petra. 2010. 'The Luwian adverbs zanta 'down' and *ānni 'with, for, against." In Acts of the VIIth International Conference of Hittitology in Çorum, 2531 August 2008, edited by Aygül Süel, 299-318.

Gordon, Matthew K. 2016. Phonological Typology. Oxford / New York: Oxford University Press.

Hagège, Claude, and André Haudricourt. 1978. La phonologie panchronique. Paris: Presses Universitaires de France.

Ham, William. 2001. Phonetic and Phonological Aspects of Geminate Timing. New York: Routledge.

Hansen, Benjamin B. 2012. "The Perceptibility of Duration in the Phonetics and Phonology of Contrastive Consonant Length." PhD thesis, University of Texas at Austin.

Hansen, Benjamin B., and Scott Myers. 2017. "The consonant length contrast in Persian: production and perception." Journal of the International Phonetic Association 47 (2): 183-205.

Hoffner, Harry A., and H. Craig Melchert. 2008. A Grammar of the Hittite Language. Vol. I: Reference Grammar. Winona Lake, IN: Eisenbrauns.

Hrozný, Friedrich. 1917. Die Sprache der Hethiter. Leipzig: J.C. Hinrichs.

Hyllested, Adam. to appear. "Did Proto-Indo-European have a word for wheat? Hittite 
šeppit $(t)$ - revisited and the rise of post-PIE cereal terminology." In Dispersals and Diversification: Linguistic and Archaeological Perspectives on the Early Stages of IndoEuropean, edited by Matilde Serangeli and Thomas Olander. Leiden / Boston: Brill. Hyman, Larry M. 1976. "Phonologization." In Linguistic Studies Presented to Joseph H. Greenberg, edited by Alphonse Juilland, 407-418. Saratoga, CA: Anna Libri.

Hyman, Larry M. 2013. "Enlarging the scope of phonologization." In Origins of Sound Change: Approaches to Phonologization, edited by Alan C.L. Yu, 3-28. Oxford / New York: Oxford University Press.

Jäntti, S.A. Oscar. 2017. "Geminate Stops in Anatolian: Evidence and Typological Implications.” Master's thesis, Leiden University.

Jasanoff, Jay H. 2003. Hittite and the Indo-European Verb. Oxford / New York: Oxford University Press.

Jasanoff, Jay H. 2017. "The impact of Hittite and Tocharian: rethinking Indo-European in the twentieth century and beyond." In The Handbook of Comparative and Historical Indo-European Linguistics, edited by Jared S. Klein, Brian D. Joseph, and Matthias Fritz, 220-238. Berlin / New York: de Gruyter.

Kawahara, Shigeto. 2007. "Sonorancy and geminacy." University of Massachusetts Occasional Papers in Linguistics 31: 145-186.

Kawahara, Shigeto, and Melanie Pangilinan. 2017. "Spectral continuity, amplitude changes, and perception of length contrasts." In The Phonetics and Phonology of Geminate Consonants, edited by Haruo Kubozono, 13-33. Oxford / New York: Oxford University Press.

Keyser, Samuel J., and Kenneth N. Stevens. 2001. "Enhancement Revisited." In Ken Hale: A Life in Language, edited by Michael Kenstowicz, 271-291. Cambridge, MA: M.I.T. Press.

Keyser, Samuel J., and Kenneth N. Stevens. 2006. "Enhancement and overlap in the speech chain." Language 82 (1): 33-63.

Kim, Ronald. 20oo. “'To drink' in Anatolian, Tocharian, and Proto-Indo-European." Historische Sprachforschung 113: 151-170.

Kimball, Sara. 1999. Hittite Historical Phonology. Innsbruck: Institut für Sprachwissenschaft der Universität Innsbruck.

Kimball, Sara. 2015. "Review Article: A. Kloekhorst (2014), Accent in Hittite." Kratylos 6o: $18-42$.

Kiparsky, Paul. 20o6. “The amphichronic program vs. Evolutionary Phonology." Theoretical Linguistics 32 (2): 217-236.

Kiparsky, Paul. 20o8. "Universals constrain change; change results in typological generalizations." In Linguistic Universals, edited by Jeff Good, 23-53. Oxford / New York: Oxford University Press.

Kirby, James P. 2010. “Cue Selection and Category Restructuring in Sound Change." PhD thesis, University of Chicago. 
Kisseberth, Charles. 1970. "On the functional unity of phonological rules." Linguistic Inquiry 1: 291-306.

Kloekhorst, Alwin. 2006. "Initial laryngeals in Anatolian." Historische Sprachforschung 119: 77-108.

Kloekhorst, Alwin. 2008. Etymological Dictionary of the Hittite Inherited Lexicon. Leiden / Boston: Brill.

Kloekhorst, Alwin. 2010. "Initial stops in Hittite (with an excursus on the spelling of stops in Alala Akkadian)." Zeitschrift für Assyriologie und vorderasiatische Archäologie 100 (2): 197-241.

Kloekhorst, Alwin. 2014. Accent in Hittite: A Study in Plene Spelling, Consonant Gradation, Clitics, and Metrics. Wiesbaden: Harrassowitz.

Kloekhorst, Alwin. 2016. "The Anatolian stop system and the Indo-Hittite hypothesis." Indogermanische Forschungen 121: 213-247.

Kortlandt, Frederik. 2010. “An outline of Proto-Indo-European." In Studies in Germanic, Indo-European, and Indo-Uralic, 37-45. Amsterdam: Rodopi.

Kraehenman, Astrid. 2001. "Swiss German stops: geminates all over the word." Phonology 18: 109-145.

Kraehenman, Astrid, and Aditi Lahiri. 2008. "Duration differences in the articulation and acoustics of Swiss German word-initial geminate and singleton stops." Journal of the Acoustical Society of America 123 (4446-4455): 2008.

Kühne, Cord. 1986. "Hethitisch auli- und einige Aspekte altanatolischer Opferpraxis." Zeitschrift für Assyriologie und vorderasiatische Archäologie 76: 85-117.

Kümmel, Martin J. 2007. Konsonantenwandel: Bausteine des Lautwandels und ihre Konsequenzen für die vergleichende Rekonstruktion. Wiesbaden: Reichert.

Ladefoged, Peter, and Keith Johnson. 2011. A Course in Phonetics. 6th ed. Boston: Wadsworth.

Lahiri, Aditi, and Jorge Hankamer. 1988. "The timing of geminate consonants." Journal of Phonetics 16: 327-338.

Lindemann, Fredrik O. 1965. "Note phonologique sur hittite eku- 'boire'." Revue hittite et asianique 23: 29-32.

Lisker, Leigh. 1957. "Closure duration and the intervocalic voiced-voiceless distinction in English." Language 33: 42-49.

Lisker, Leigh. 1978. "Rapid vs. rabid: A catalogue of acoustic features that may cue the distinction." Status Report on Speech Research SR-54. Haskins Laboratories.

Lisker, Leigh. 1986. "'Voicing' in English: a catalogue of acoustic features signaling /b/ versus /p/ in trochees." Language and Speech 29 (1): 3-11.

Lisker, Leigh, and Arthur S. Abramson. 1964. "A cross language study of voicing in initial stops: acoustical measurements." Word 20 (3): 384-422.

Lisker, Leigh, and Arthur S. Abramson. 1970. "The voicing dimension: some experiments in comparative phonetics." In Proceedings of the 6th International Congress of the Phonetic Sciences, Prague, 7-13 September 1967, 563-567. 
Lombardi, Linda. 1999. "Positional faithfulness and voicing assimilation in Optimality Theory." Natural Language and Linguistic Theory 17: 267-302.

Lotz, John, Arthur S. Abramson, Louis J. Gerstman, Frances Ingemann, and William J. Nemser. 1960. "The perception of English stops by speakers of English, Spanish, Hungarian, and Thai: a tape cutting experiment." Language and Speech 3: 7176.

Luce, Paul A., and Jan Charles-Luce. 1985. "Contextual effects on vowel duration, closure duration, and the consonant/vowel ratio in speech production." Journal of the Acoustical Society of America 78 (6): 1949-1957.

Mayrhofer, Manfred. 1986. Indogermanische Grammatik, Band I/2: Lautlehre. Heidelberg: Carl Winter.

Melchert, H. Craig. 1993. "A new Anatolian 'law of finals." Journal of Ancient Civilizations 8: $105^{-113}$.

Melchert, H. Craig. 1994. Anatolian Historical Phonology. Amsterdam / Atlanta: Rodopi. Melchert, H. Craig. 2003. “PIE 'thorn' in Cuneiform Luvian?” In Proceedings of the Fourteenth Annual UCLA Indo-European Conference, Los Angeles, November 8-9 2002, edited by Karlene Jones-Bley, Martin E. Huld, Angela Della Volpe, and Miriam R. Dexter, 145-161. Washington, D.C.: Institute for the Study of Man.

Melchert, H. Craig. 2007/8. "Neuter stems with the suffix *-(e)n-in Anatolian and ProtoIndo-European." Die Sprache 47 (2): 182-191.

Melchert, H. Craig. 2009. "Hittite hi-verbs from adverbs." In Protolanguage and Prehistory: Fachtagung der Indogermanischen Gesellschaft, Krakau 11. bis 15. Oktober 2004, edited by Rosemarie Lühr and Sabine Ziegler. Wiesbaden: Reichert.

Melchert, H. Craig. 2011. “The PIE verb for 'to pour' and medial * $h_{3}$ in Anatolian." In Proceedings of the 22nd Annual UCLA Indo-European Conference, edited by Stephanie W. Jamison, H. Craig Melchert, and Brent Vine, 127-132. Bremen: Hempen.

Melchert, H. Craig. 2012. "Hittite hi-verbs of the type $-\bar{a} C_{1} i,-a C_{1} C_{1}$ anzi." Indogermanische Forschungen 117: 173-185.

Melchert, H. Craig. 2014. “'Narten formations' versus 'Narten roots'” Indogermanische Forschungen 119: 251-258.

Melchert, H. Craig. 2018. "Hittite and Indo-European: revolution and counterrevolution." In 100 Jahre Entzifferung des Hethitischen: Morphosyntaktische Kategorien in Sprachgeschichte und Forschung. Proceedings of the Arbeitstagung of the Indogermanische Gesellschaft, Marburg, 21. bis 23. September 2015, edited by Elisabeth Rieken, 289-294. Wiesbaden.

Melchert, H. Craig. 2019. "Hittite historical phonology after 100 years (and after 20 years)." In Hrozný and Hittite: The First 100 Years. Proceedings of the International Conference Held at Charles University, Prague, 11-14 November 2015, edited by Ronald I. Kim, Jana Mynářová, and Peter Pavúk. (Ms. available at: http://linguistics.ucla.edu/ people/Melchert/melchertprague2015.pdf). 
Melchert, H. Craig. to appear. "The medio-passive in transition from Old to New Hittite." In a forthcoming Festschrift.

Melchert, H. Craig. to appear c. "The position of Anatolian." In Handbook of IndoEuropean Studies, edited by Andrew Garrett and Michael Weiss. Oxford / New York: Oxford University Press.

Morpurgo-Davies, Anna. 1982. "Dentals, rhotacism and verbal endings in the Luwian languages." Zeitschrift für vergleichende Sprachforschung 96: 245-270.

Mudge, C.L. 1931. "Ten Hittite etymologies." Language 7: 252-253.

Muller, Jennifer. 2001. “The Phonology and Phonetics of Word-Initial Geminates.” PhD thesis, Ohio State University.

Nussbaum, Alan J. 1976. “Caland's 'Law' and the Caland System.” PhD thesis, Cambridge, MA: Harvard University; Harvard University.

Oettinger, Norbert. 1979. Die Stammbildung des hethitischen Verbums. Nürnberg: Hans Carl.

Oettinger, Norbert. 2009. "Die Derivationsbasis von idg. *daiwér- ( ${ }^{*}$ saiwér- $)$ 'Bruder des Ehemannes." In * $\mathrm{h}_{2}$ nr: Festschrift für Heiner Eichner, edited by Robert Nedoma and David Stifter, 127-131. Wiesbaden: Harrassowitz.

Oettinger, Norbert. 2017. “The morphology of Anatolian.” In Handbook of Comparative and Historical Indo-European Linguistics, edited by Jared S. Klein, Brian Joseph, and Matthias Fritz, 256-273. Berlin / New York: de Gruyter.

Oettinger, Norbert. 2013-2014. "Die Indo-Hittite-Hypothese aus heutiger Sicht." Münchener Studien zur Sprachwissenschaft 67 (2): 149-176.

Ohala, John J. 1981. "The listener as a source of sound change." In Papers from the Parasession on Language and Behavior, edited by Carrie S. Masek, Robert A. Hendrick, and Mary F. Miller, 178-203. Chicago: Chicago Linguistic Society.

Ohala, John J. 1993a. “Sound change as nature's speech perception experiment." Speech Communication 13 (2): 155-161.

Ohala, John J. 1993b. "The phonetics of sound change." In Historical Linguistics: Problems and Perspectives, edited by Charles Jones, 237-278. Harlow: Longman.

Pająk, Bożena. 20o9. "Contextual constraints on geminates: the case of Polish." In Proceedings of the 35th Annual Meeting of the Berkeley Linguistics Society, edited by Iksoo Kwon, Hannah Pritchett, and Justin Spence, 269-28o.

Pająk, Bożena. 2013. "Non-intervocalic geminates: typology, acoustics, perceptibility." San Diego Linguistics Papers 4: 2-27.

Pedersen, Holgar. 1938. Hittitisch und die anderen indoeuropäischen Sprachen. Copenhagen: Levin \& Munksgaard.

Pedersen, Holger. 1933. "Zur Frage nach der Urverwandtschaft des Indoeuropaïschen mit dem Ugrofinnischen." Memoires de la Société Finno-Ougrienne 67:308-325.

Podesva, Robert. 2002. "Segmental constraints on geminates and their implications for typology." Paper presented at the 76th Annual Meeting of the Linguistic Society of America, Philadelphia, 3-6 January 2002. 
Pozza, Marianna. 2011. La grafia delle occlusive intervocaliche in ittito: verso una riformulazione della Lex Sturtevant. Roma: Il Calamo.

Pozza, Marianna. 2012. "Reflections on some problematic cases for Sturtevant's Law." Indogermanische Forschungen 117: 257-282.

Prince, Alan, and Paul Smolensky. 1993/2004. Optimality Theory: Constraint Interaction in Generative Grammar. Oxford / Malden, MA: Blackwell.

Puhvel, Jaan. 1997. Hittite Etymological Dictionary, Vol. 4: Words beginning with K. Berlin / New York: de Gruyter.

Pycha, Anne. 2010. "A test case for the phonetics-phonology interface: gemination restrictions in Hungarian." Phonology 27:119-152.

Randolph, Mark A. 1989. "Syllable-based Constraints on Properties of English Sounds." $\mathrm{PhD}$ thesis, Massachusetts Institute of Technology.

Raphael, Lawrence J. 2005. "Acoustic cues to the perception of segmental phonemes." In The Handbook of Speech Perception, edited by David B. Pisoni and Robert E. Remez, 182-206. Malden, MA / Oxford: Blackwell.

Reeds, James A., and William S-Y. Wang. 1961. "The perception of stops after s." Phonetica 6: $78-81$.

Repp, Bruno H. 1982. "Phonetic trading relations and context effects: new experimental evidence for a speech mode of perception." Psychological Bulletin 92: 81110.

Ridouane, Rachid. 2003. "Suites de consonnes en berbère: phonétique et phonologie." PhD thesis, Université de la Sorbonne nouvelle.

Ridouane, Rachid. 2007. "Gemination in Tashlhiyt Berber: an acoustic and articulatory study." Journal of the International Phonetic Association 37: 119-142.

Rieken, Elisabeth. 1999. Untersuchungen zur nominalen Stammbildung des Hethitischen. Wiesbaden: Harrassowitz.

Ringen, Catherine O., and Robert M. Vago. 2010. “Geminates: heavy or long?" In Handbook of the Syllable, edited by Charles E. Cairns and Eric Raimy, 155-169. Leiden / Boston: Brill.

Rose, Sharon. 2000. "Rethinking geminates, long-distance geminates, and the OCP." Linguistic Inquiry 31: 85-122.

Sandell, Ryan. 2015. "Obligatory Contour Principle effects in Indo-European phonology: statistical evidence and the morphology-phonology interface." In Proceedings of the 26th Annual UCLA Indo-European Conference, edited by Stephanie W. Jamison, H. Craig Melchert, and Brent Vine, 141-16o. Bremen: Hempen.

Schindler, Jochem. 1967. "Zu hethitisch nekuz." Zeitschrift für vergleichende Sprachforschung 81: 290-303.

Simon, Zsolt. 2017. "The Anatolian stop system and the Indo-Hittite hypothesisrevisited." Paper presented at "The Split: Reconstructing Early Indo-European Language and Culture," Copenhagen, 13-15 March 2017. 
Steriade, Donca. 1994. "Positional neutralization and the expression of contrast." Ms. (Available at http://lingphil.mit.edu/papers/steriade/contrastive-gesture.pdf).

Steriade, Donca. 1997. "Phonetics in phonology: the case of laryngeal neutralization." Ms. (Available at http://linguistics.ucla.edu/people/steriade/papers/PhoneticsInPh onology.pdf).

Sturtevant, Edgar H. 1929. "The relationship of Hittite to Indo-European.” Transactions and Proceedings of the American Philological Association 6o: 25-37.

Sturtevant, Edgar H. 1932. "The development of stops in Hittite." Journal of the American Oriental Society 52: 1-12.

Sturtevant, Edgar H. 1933. A Comparative Grammar of the Hittite Language. Philadelphia: The Linguistic Society of America.

Thurgood, Graham. 1993. "Geminates: a cross-linguistic examination." In Papers in Honor of Frederick H. Brengelman on the Occasion of the Twenty-fifth Anniversary of the Department of Linguistics, CSU Fresno, edited by Joel A. Nevis, Gerald McMenamin, and Graham Thurgood, 129-139. Fresno: CSU Fresno Department of Linguistics.

Vaan, Michiel de. 2008. Etymological Dictionary of Latin and the other Italic Languages. Leiden / Boston: Brill.

Vennemann, Theo. 1972. "Rule inversion." Lingua 29: 209-242.

Vijūnas, Aurelijus. 2009. The Indo-European Primary T-Stems. Innsbruck: Institut für Sprachen und Literaturen der Universität Innsbruck.

Wang, William S-Y. 1959. "Transition and release as perceptual cues for final plosives.” Journal of Speech, Language, and Hearing Research 2: 66-73.

Watkins, Calvert. 1969. Geschichte der indogermanischen Verbalflexion (Indogermanische Grammatik: III/, Formenlehre). Heidelberg: Carl Winter.

Watkins, Calvert. 1976. "Towards Proto-Indo-European syntax: problems and pseudoproblems." In Papers from the Parasession on Diachronic Syntax, edited by Sanford B. Steever, Salikoko S. Mufwene, and Carol C. Walker, 305-326. Chicago: Chicago Linguistic Society.

Watkins, Calvert. 1998. "Proto-Indo-European: comparison and reconstruction." In The Indo-European Languages, edited by Anna Giacalone Ramat and Paolo Ramat, 2573. London / New York: Routledge.

Watkins, Calvert. 2001. "An Indo-European linguistic area and its characteristics: Ancient Anatolia. Areal diffusion as a challenge to the Comparative Method?" In Areal Diffusion and Genetic Inheritance: Problems in Comparative Linguistics, edited by Alexandra Y. Aikhenvald and R.M.W. Dixon, 44-63. Oxford / New York: Oxford University Press.

Weiss, Michael. 2011. Outline of the Historical and Comparative Grammar of Latin. Ann Arbor / New York: Beech Stave Press.

Weiss, Michael. 2014. “The Comparative Method." In Routledge Handbook of Historical 
Linguistics, edited by Claire Bowern and Bethwyn Evans, 127-145. New York: Routledge.

Weiss, Michael. 2016. "The Proto-Indo-European laryngeals and the name of Cilicia in the Iron Age." In Tavet Tat Satyam: Studies in Honor ofJared S. Klein on the Occasion of His Seventieth Birthday, edited by Andrew M. Byrd, Jessica DeLisi, and Mark Wenthe, 331-340. Ann Arbor / New York: Beech Stave Press.

Wetzels, W. Leo, and Joan Mascaró. 20o1. "The typology of voicing and devoicing." Language 77 (2): 207-244.

Wright, Richard. 2004. "A review of perceptual cues and cue robustness." In Phonetically-Based Phonology, edited by Bruce Hayes, Robert Kirchner, and Donca Steriade, 34-57. Cambridge, UK / New York: Cambridge University Press.

Yakubovich, Ilya. 2006a. "The free-standing genitive and hypostasis in Hittite." Journal of Near Eastern Studies 65 (1): 39-50.

Yakubovich, Ilya. 20o6b. "Were Hittite kings divinely anointed? A Palaic invocation for Hittite religion." Journal of Ancient Near Eastern Religions 5: 107-137.

Yates, Anthony D. 2016. "Hittite stressed vowel lengthening and the phonology-orthography interface." In Proceedings of the 27th Annual UCLA Indo-European Conference, edited by David M. Goldstein, Stephanie W. Jamison, and Brent Vine, 235-257. Bremen: Hempen.

Yates, Anthony D. 2017. "Lexical Accent in Cupeño, Hittite, and Indo-European." PhD thesis, University of California, Los Angeles.

Yates, Anthony D. 2018. "Some basics of Indo-European phonology." Paper presented at the 37th Annual East Coast Indo-European Conference, Ann Arbor, MI, 14-17 June 2018 (Handout available at: http://www.adyates.com/research/).

Yates, Anthony D., and Sam Zukoff. 2018. "The phonology of Anatolian reduplication: synchrony and diachrony." Indo-European Linguistics 6: 201-27o.

Yoshida, Kazuhiko. 1991. "Reconstruction of Anatolian verbal endings: the third person plural preterites." Journal of Indo-European Studies 19: 359-374.

Yoshida, Kazuhiko. 1993. "Notes on the prehistory of preterite verbal endings in Anatolian." Historische Sprachforschung 106: 26-35.

Yoshida, Kazuhiko. 2001. "Hittite $n u-z a$ and related spellings." In Akten des IV. Internationalen Kongresses für Hethitologie, Würzburg, 4.-8. Oktober 1999, edited by Gernot Wilhelm, 721-729. Wiesbaden: Harrassowitz.

Yoshida, Kazuhiko. 2002. "Observations on some cuneiform spellings: epithetic or graphic?" In Proceedings of the 13th Annual UCLA Indo-European Conference, Los Angeles, 9-10 November 2001, edited by Karlene Jones-Bley, Martin E. Huld, Angela Della Volpe, and Miriam Robbins Dexter, ${ }_{165}^{-176}$. Washington, D.C.: Institute for the Study of Man.

Yoshida, Kazuhiko. 2011. "Proto-Anatolian as a mora-based language." Transactions of the Philological Society 109 (1): 92-108. 
Yoshida, Kazuhiko. 2016. "Hittite mediopassives in -atta." In Sahasram Ati Srajas: IndoEuropean and Indo-Iranian Studies in Honor of Stephanie W.Jamison, edited by Dieter Gunkel, Joshua T. Katz, Brent Vine, and Michael Weiss, 499-511. Ann Arbor / New York: Beech Stave Press.

Yu, Alan C. 2004. "Explaining final obstruent voicing in Lezgian: phonetics and history." Language 8o (1): 73-97.

Zukoff, Sam. 2017. "Indo-European Reduplication: Synchrony, Diachrony, and Theory." PhD thesis, Massachusetts Institute of Technology. 